\title{
The effect of listing price strategy on real estate negotiations: An experimental study
}

\author{
Eric Cardella ${ }^{\mathrm{a}, *}$, Michael J. Seiler ${ }^{\mathrm{b}, 1}$ \\ ${ }^{a}$ Rawls College of Business, Texas Tech University, Lubbock, TX 79409, United States \\ ${ }^{\mathrm{b}}$ Raymond A. Mason School of Business, The College of William \& Mary, P.O. Box 8795, Williamsburg, VA 23187-8795, United States
}

\section{A R T I C L E I N F O}

\section{Article history:}

Received 19 June 2015

Received in revised form 9 November 2015

Accepted 16 November 2015

Available online 23 November 2015

\section{JEL classification: \\ R30 \\ C70 \\ C91 \\ L11}

PsycINFO classification:

2340

3020

3900

3920

3940

Keywords:

Listing price

Real estate

Negotiation

Flexible price

Experiment

\begin{abstract}
A B S T R A C T
When selling a home, an important decision facing the homeowner is choosing an optimal listing price. This decision will depend in large part on how the chosen list price impacts the post negotiation final sale price of the home. In this study, we design an experiment that enables us to identify how different types of common list price strategies affect housing negotiations. Specifically, we examine how rounded, just below, and precise list prices impact the negotiation behavior of the buyer and seller and, ultimately, the final sale price of the home. Our results indicate that the initial list price strategy does play an important role in the negotiation process. Most notably, a high precise price generates the highest final sale price, smallest percentage discount off the list price, and the largest fraction of the surplus to the seller, while just below pricing leads to the lowest final price, largest percentage discount, and smallest fraction of the surplus to the seller. This pattern seems to be largely driven by sellers making persistently higher and more precise counter-offers throughout the negotiation process when the initial list price is high precise. Interestingly, these effects generally attenuate with negotiating experience. Importantly, our experimental results are generally consistent, both in direction and magnitude, with the limited transactions-based empirical studies relating to real estate listing prices.
\end{abstract}

(c) 2015 Elsevier B.V. All rights reserved.

\section{Introduction}

A key decision in selling a home is selecting the listing price. Typically, this initial list price serves as the starting point in the negotiation process, a process which ultimately determines the final sale price. Given the magnitude of house prices, even a small percentage change in the final sale price can have significant financial ramifications for the seller. As a result, one of the chief aims of the seller is choosing the optimal list price that will generate the highest sale price. In making this

\footnotetext{
* Corresponding author. Tel.: +1 (806) 8347482 .

E-mail addresses: eric.cardella@ttu.edu (E. Cardella), Michael.Seiler@mason.wm.edu (M.J. Seiler).

1 Tel.: +1 (757) 5856100 .
} 
decision, it is imperative to understand how the choice of list price will impact the negotiation process and, consequently, the final sale price.

Although the set of possible list prices is large, since homes tend to sell for six figure amounts, real estate list prices tend to be clustered (Allen \& Dare, 2004, 2006; Beracha \& Seiler, 2014; Mason, Lee, Wiley, \& Ames, 2013; Palmon, Smith, \& Sopranzetti, 2004; Thomas, Simon, \& Kadiyali, 2010). Specifically, a disproportionate number of homes tend to be listed at prices where the last three digits are 000,500 , or 900 , or the last four digits are $0,000,5,000$ or 9,000 . For example, Beracha and Seiler (2014) consider over 300,000 real estate transactions and document that $14 \%$ are listed with a price ending in $0,000,16 \%$ ending with 5,000, and 35\% ending in 9,000. Thomas et al. (2010) find that over 62\% of the houses in their sample of over 16,000 transactions are listed with prices ending in 000. Mason et al. (2013) find that that in a sample of just over 1,500 houses listed on Zillow, over $70 \%$ have list prices with at least three trailing zeros. ${ }^{2}$ Given the extensive clustering of list prices observed empirically, the motivation of this study is to shed light on how the type of list price impacts the negotiation process and, ultimately, the final sale price.

To do so, we develop a novel experimental design where we systematically vary the type of list price, enabling us to explore the effect of the initial list price strategy on purchase negotiations. Specifically, we study how variation in the thousands digit of the list price affects the negotiation behavior of buyers and sellers and, consequently, the final sale price. We consider three different types of listing price strategies: (i) rounded, (ii) just below, and (iii) precise. Consistent with the characterization used in Beracha and Seiler (2014), a "round" price is one where the thousands digit is either 0 or 5; "just below" is a price where the thousands digit is either 4 or 9; and a "precise" price is defined as having a thousands digit of either 1, 2, 3, 6, 7, or 8.

Within the experiment, participants engage in a stylized, bi-lateral housing negotiation. As part of the experimental design, we exogenously vary the list price strategy across treatments while holding the other aspects of the negotiation process constant. In the "rounded" $(\mathrm{R})$ treatment, the list price is set to $\$ 200,000$; in the "just below" (JB) treatment the list price is set to $\$ 199,000$. For "precise" pricing, we consider two variations: the high precise (HP) treatment features a list price of $\$ 201,326$ whereas the low precise (LP) treatment features a list price of $\$ 198,674$. This systematic manipulation of the list price strategy enables us to compare outcomes across treatments to identify the corresponding effect of the list price strategy. Furthermore, we are able to observe all intermediate steps within the negotiation process including the entire sequence of offers and counter-offers, which allows us to identify how the various list price strategies separately affect the negotiation behavior of buyers and sellers. This level of investigation is not possible using transactions data because with transactions only the outcome is observable.

A small body of literature exists that focuses on the relation between types of list prices and real estate sales. Allen and Dare $(2004,2006)$ use transactions data from Florida and document that "charm" pricing is associated with higher final sale prices and smaller negotiated discounts off the list price, respectively. Palmon et al. (2004) use transactions data from Texas and find that "just below even" list prices are associated with lower final sale prices, compared to "even" list prices. ${ }^{3}$ Thomas et al. (2010) use transactions data from Long Island and South Florida, and find that "precise" list prices (those ending in 000) lead to higher final prices. Similarly, Janiszewski and Uy (2008) use transactions data from Florida and find that more precise list prices lead to a higher sale price to list price ratio (i.e., a lower negotiated discount). The most closely related study to ours is a recent paper by Beracha and Seiler (2014) who use data on over 300,000 residential real estate transactions in Hampton Roads, Virginia, spanning 1993-2011. The authors find that just below pricing is associated with the largest negotiated discounts. However, because just below pricing is also associated with the greatest degree of over-pricing by sellers, just below pricing leads to the greatest net proceeds to the seller. Because of the endogeneity of list price strategies, it is difficult to identify the effect of list prices on the size of the negotiated discount and the final price using empirical transaction data. By systematically and exogenously varying list price strategies, our study advances this prior empirical work by identifying the causal effect of various list price strategies on the negotiation process and the final negotiated price.

In particular, we contend that a controlled experiment affords us several advantages relative to these prior transactionsbased empirical studies. First, we are able to systematically control for the fundamental value of the property being transacted, which is latent for real properties. This mitigates the endogeneity problem resulting from systematic over/underpricing associated with certain list price strategies (e.g., Beracha and Seiler (2014), who document over-pricing of homes listed at a just below price). Second, we are able to abstract from the dimension of housing quality. Abstracting away from quality is important because with transactions data, housing quality is either imprecisely observed or not observed at all, which can lead to selection bias when estimating the effect of list prices. In other words, sellers with lower or higher quality properties may systematically gravitate toward certain list price strategies. ${ }^{4}$ Because the underlying quality of the property is

\footnotetext{
2 As part of the same study, Mason et al. (2013) also conduct a pilot study where they ask experienced executives and MBA students to make initial price offers for goods of various prices. Their pilot study revealed that $48 \%$ of the prices were what they termed "maximally round" containing only one leading nonzero number followed by all zeros; furthermore, none of the prices were specified precisely down to the ones digit.

3 Allen and Dare (2004) define a "charm" price as a price ending in 500, 900, 4,900, 5,000, 9,000, or any other non-zero number. Hence, their characterization of a charm price does not match either of the three list price strategies we consider, and it encompasses (as a subset) what we define as just below and precise. Furthermore, their broad characterization of a charm price includes variation in all digits up to the thousands digit; thus, there is no clear way to connect our results regarding the effect of rounded, just below, or precise pricing with the results from Allen and Dare on charm pricing. Palmon et al. (2004) examine variations in the hundreds digit and characterize "even" prices as those ending with 000 and "just below even" as those ending with 900 . Thus, their definitions would be along the lines of our definitions of round and just below pricing, respectively.

4 Palmon et al. (2004) point to such a concern by noting "selection bias might be present if sellers' decision to list their properties at even or just-below-even prices is associated with some unobserved variables that are correlated with the inherent value of the property" (p. 129).
} 
unobservable in the field, it is not possible using transactions data to separate the effect of list prices on final transaction prices due to possible differences in property quality; this problem is overcome in an experimental setting. Third, by randomly and exogenously assigning list price strategies within a negotiating dyad, we are able to avoid possible selection bias based on the negotiating style/ability of sellers. Substantial heterogeneity is likely among sellers in the housing market, and sellers of either low or high negotiation ability may systematically gravitate toward certain list price strategies. The endogenous selection of list price strategy by sellers in transactions data, again, makes it difficult to isolate the effect of list prices on final sale prices. However, by randomly and exogenously assigning sellers to list price strategies in the experiment, we can identify (via average treatment effects) the impact of list pricing strategies.

Overall, our results indicate that the list price strategy can impact negotiations. In particular, we find that high precise pricing leads to the highest final sale price. With regard to negotiated discount, high precise pricing results in the smallest percentage discount and the largest share of the surplus to the seller, while just below pricing results in the largest percentage discount and the smallest share of the surplus to the seller, relative to the list price. Our data also suggest that list prices affect buyers and sellers differently. Namely, buyers make the lowest offers when the price is rounded, while sellers make the lowest counter-offers when the price is just below. Furthermore, the effect of the list price has a more persistent effect on sellers throughout the negotiation process; namely, sellers persistently make the highest counter-offers and more precise counter-offers under a high precise initial list price, which leads to higher final sale prices under high precise pricing. Lastly, we find that negotiating experience tends to attenuate the observed effects.

Using an experimental approach to ascertain the effects of listing price strategy on real estate negotiations affords many advantages over transactions-based empirical studies: most notably the ability to draw causal inference and observe the intermediate steps of the negotiation process. However, we acknowledge that our experimental design is stylized and abstracts away from some of the characteristics of practical real estate negotiations. That said, our main experimental results regarding the effects of the various listing price strategies are generally consistent, both in magnitude and direction, with the limited prior transactions-based empirical studies of Janiszewski and Uy (2008), Thomas et al. (2010), and Beracha and Seiler (2014). This establishes an increased degree of credibility to our experimental results. Perhaps even more importantly, the fact that we generate results in our experimental setting that are similar in spirit to the transactions-based results provides suggestive evidence that listing price strategy can directly influence real estate negotiations, in practice; namely, the observed empirical variation in final prices and negotiated discounts across various listing price strategies is likely attributed, in large part, to the chosen list price strategy rather than other unobserved or imprecisely observed factors.

The main motivation of this study is to explore the impact of various list price strategies on final sale prices within the context of real estate negotiations. That said, real estate is by no means the only type of good where the list (or posted) price is flexible and generally viewed as negotiable. Other examples of flexible price goods include: new and used automobiles, goods sold in secondary markets, consumer durable goods, and sub-contracted services. For discussion on the motivation for flexible or "haggle" prices, the actual negotiation process in these settings, and the factors that influence this process, we refer readers to Kassaye (1990) and Stroeker and Antonides (1997). In terms of broader implications, we conjecture that our main results on how list price strategies impact real estate negotiations are applicable, more generally, in these other markets where list prices are also negotiable. Most notably, our results suggest that setting precise prices for these negotiable goods will result in the least aggressive negotiation behavior by buyers and, consequently, yield the highest final sale prices.

\section{Related literature}

While the primary motivation of this study is to investigate list price strategies in residential real estate transactions, a mature body of literature does exist relating, more generally, to list prices in consumer goods markets. In particular, the presence of a disproportionate number of prices ending in 9 has been empirically documented (Friedman, 1967; Holdershaw, Gendall, \& Garland, 1997; Kreul, 1982; Schindler \& Kirby, 1997; Schindler \& Wiman, 1989; Twedt, 1965). ${ }^{5}$ Furthermore, several studies have documented that prices ending in 9 can be effective in generating higher sales (Gendall, Holdershaw, \& Garland, 1997; Kalyanam \& Shively, 1998; Schindler \& Kibarian, 1996; Stiving \& Winer, 1997; Gedenk \& Sattler, 1999; Anderson \& Simester, 2003; Bizer \& Schindler, 2005). The idea is that consumers tend to drop-off the right most digits (Basu, 1997, 2006; Bizer \& Schindler, 2005) or that there is a left-digit bias (Korvorst \& Damian, 2008; Poltrock \& Schwartz, 1984; Thomas \& Morwitz, 2005); hence, consumers pay less attention to those right-most digits. ${ }^{6}$ Relatedly, Janiszewski and Uy (2008) find that more precise anchoring values lead to lower adjusted judgement values made by participants compared to their corresponding rounded equivalent.

While these prior studies suggest list price strategies may influence residential real estate transactions, they may not translate directly. The reason is that in real estate transactions, unlike many consumer goods markets, the list price is generally viewed as negotiable (Allen \& Dare, 2006; Beracha \& Seiler, 2014). That is, the list price serves as the starting point of

\footnotetext{
5 The phenomenon of prices ending in 9 has been referred to and explored under various terms including pricing in the nines (Basu, 1997, 2006), 9-ending pricing (Bizer \& Schindler, 2005; Gedenk \& Sattler, 1999), odd-pricing (Evans \& Berman, 1997; Monroe, 1979), and just below pricing (Stiving \& Winer, 1997).

${ }^{6}$ Formal models of inattention bias have been developed by Chetty, Looney, and Kroft (2009), DellaVigna (2009), and Finkelstein (2009). Lacetera, Pope, and Sydnor (2012) provide empirical evidence of inattention bias with respect to rightmost digits using used car transaction data; specifically, the authors find that there are discontinuous sales price drops at 10,000 and 1,000 mile odometer thresholds.
} 
the negotiations. Furthermore, purchase prices in real estate transactions tend to be much larger than most other retail consumer goods. As a result, list price strategies may impact the negotiation process between the buyer and seller differently than just the buyer's decision about whether to purchase a good at a fixed posted price. ${ }^{7}$ That said, we view this study as contributing to the extant literature on list price strategies by investigating their effect on negotiated outcomes in real estate transactions where prices are negotiable.

With regard to real estate transactions, there is a body of literature on the relation between list prices and sale prices (e.g., Anglin, Rutherford, \& Springer, 2003; Han \& Strange, 2014; Haurin, Haurin, Nadauld, \& Sanders, 2010; Haurin, McGreal, Adair, Brown, \& Webb, 2013; Knight, 2002; Kristensen \& Gärling, 1997b, 2000; Miller \& Sklarz, 1987; Northcraft \& Neale, 1987; White, Valley, Bazerman, Neale, \& Peck, 1994). ${ }^{8}$ However, these studies focus primarily on how the magnitude of the list price or relative position of the list price to the fundamental property value or reservation values impact final sale prices and time on the market (as opposed to examining the type of list price strategy employed). ${ }^{9}$ A few prior empirical studies look specifically at list price strategies (Allen \& Dare, 2004, 2006; Palmon et al., 2004; Thomas et al., 2010; Beracha \& Seiler, 2014). However, as discussed in the introduction, these empirical studies using transactions data provide challenges in identifying the causal impact of list price strategies. The study by Thomas et al. (2010) also provides some experimental evidence of the role of the type of list price in a real estate setting; specifically, the authors show that precise list prices of hypothetical houses for sale result in lower reported price assessments and higher reported willingness to pay among participants, compared to rounded price equivalents (i.e., prices ending in 000). We also use a controlled experiment where we systematically and randomly vary list price strategies, which enables us to causally identify how the list price impacts both the negotiation process and the final sale price. Thus, we see this study as an important and necessary step in deepening our understanding how list prices impact real estate negotiations.

With regard to flexible price markets, more generally, an important issue that arises is whether it is profitable for sellers to implement a pricing scheme where buyers can (attempt) to negotiate, or rather, should sellers commit to a fixed, nonnegotiable price. Several papers have theoretically explored this topic (Arnold \& Lippman, 1998; Bester, 1993, 1994; Desai \& Purohit, 2004; Gill \& Thanassoulis, 2009, 2015; Raskovich, 2007; Wang, 1995). Often, the optimal pricing decisions for sellers and the resulting equilibrium predictions depend, in part, on the negotiation behavior of the buyers. Thus, in terms of using these models to generate predictions about optimal seller behavior and market outcomes, it is important to understand the bargaining tendencies of buyers. However, the prior models abstract away from the possibility that the negotiation behavior of buyers may be endogenous to the chosen flexible list price. The results from this study regarding how different list price strategies impact negotiations can have important implications in other markets as to whether sellers should allow prices to be flexible and, if so, what type of list price should be set.

\section{Experimental design}

Our experimental design is centered on a stylized, bi-lateral real estate negotiation; the seller is endowed with a fictitious house for sale at an initial list price, denoted $p_{l}$. The other party is a buyer, who is tasked with trying to negotiate the purchase of the house from the seller.

\subsection{Method}

The negotiation process begins with the buyer choosing to either purchase the house at the initial list price, or make a counter-offer to the seller. Conditional on the buyer making a counter-offer, the seller then has an opportunity to either accept the buyer's counter-offer or reject it and make a counter-offer back to the buyer. If the seller accepts, then the negotiation ends. If the seller makes a counter-offer, the buyer then has an opportunity to accept the counter-offer or reject it and make a counter-offer. The negotiation continues in this alternate-offer style format until either: (i) the buyer or seller accepts the offer of the other party, or (ii) the maximum time allotment of 3-min elapses without an agreement (in which case the house is not transacted).

Sellers are privately informed of their reservation value, denoted by $r$, for the house at the beginning of the negotiation process. Similarly, buyers are privately informed at the beginning of the negotiations of their value for the house, denoted by $v$. If the buyer and seller are able to reach a negotiated agreement, then $p_{f}$ denotes the final negotiated price. In terms of payoffs, sellers are privately informed that they will receive a payoff of $p_{f}-r$ if they sell the house and a payoff of zero if they fail to sell the house. Buyers are privately informed that they will receive a payoff of $v-p_{f}$ if they buy the house and a payoff of

\footnotetext{
7 Mason et al. (2013) experimentally investigate how precise list prices can impact initial offers in simulated negotiations over various hypothetical consumer goods (with 2 digit prices), compared to rounded prices, where they characterize a precise price as a price that does not end in zero. They find that price offers are lower with a rounded price (both $\$ 1$ above and $\$ 1$ below the rounded price). The authors also find that rounded pricing leads to a lower final settlement price in a hypothetical used car negotiation (with a 4 digit price), compared to a precise price.

${ }^{8}$ Anenberg and Kung (2014) examine list price changes when nearby REO properties enter the market. Anenberg and Laufer (2014) use the spread of list price to sale price ratio as a way to create forward-looking price home indexes. Neither study approaches the level of granularity in, or focus of, list prices and their effect of the negotiation process as in our study.

${ }^{9}$ A recent paper by Pope, Pope, and Sydnor (2014) studies the role of focal points in determining the final sale price in real estate transactions, and they document significant evidence that final sale prices are likely to end in round numbers (e.g., prices divisible by $\$ 25,000$ and $\$ 50,000$ ). In analyzing a subset of their data, the authors find that the list price does not explain the observed patterns in the data.
} 
zero if they fail to buy the house. To remain as close as possible to actual residential real estate prices, and to allow for variation in the thousands digit of the list price, all monetary values are in terms of 6-figure experimental currency dollars (ECD), which are then converted into actual dollars after the experiment ends.

As the foundation of our experimental design, we consider 4 different list prices for the house, which are characterized as follows:

Rounded Price (R): $p_{l}=\$ 200,000$.

Just Below Price (JB): $p_{l}=\$ 199,000$.

High Precise Price (HP): $p_{l}=\$ 201,326$

Low Precise Price (LP): $p_{l}=\$ 198,674$.

Because a precise list price can be either above or below the rounded price, it is possible that these two different types of precise prices have different effects on the negotiation. By considering two different precise prices, one that is above the rounded price (HP) and one that is symmetrically below the rounded price (LP), we can test if and to what extent the position of the precise price matters. Furthermore, we are able to rule out the possibility that any observed difference in the precise price is merely a result of it being the lowest or highest price.

In addition to variation in the list price, another feature likely to characterize real estate negotiations is variation in the price originally paid by the seller. It is possible that this variation in the original purchase price of the house may mediate the effect of list price strategy. In particular, if the list price is close to the original purchase price, then from the perspective of the seller, the purchase price may act as an induced anchor or "price floor" in the negotiations (see Kahneman, 1992 for a discussion of anchor points in negotiations and Kristensen and Gärling, 2000 for evidence that anchor points impact negotiations). In this case, sellers may be resistant to selling the house at a price below the original price they paid for the house, i.e., these sellers may be resistant to sell at a price that generates a "perceived" loss, i.e., nominal loss-aversion (Engelhardt, 2003; Genesove \& Mayer, 2001). Thus, the seller may be less inclined to negotiate when the original purchase price is closer to the list price. ${ }^{10}$ Consequently, this rigidity by the seller could attenuate any possible effects that variation in the list price strategies may have on negotiations.

To explore whether the original purchase price paid by the seller impacts negotiations and possibly interacts with the list price strategy, we consider two different original purchase prices for the home, denoted by $p_{0}$. In the high purchase price case, sellers are privately informed, prior to the start of the negotiation, that they originally paid a price of $p_{0 h}=\$ 195,000$ for the house. In the other case, the low purchase price, sellers are privately informed that they originally paid $p_{0 l}=\$ 185,000$ for the house. The idea is that in the high price case the purchase price is set to a value that is slightly lower than the list price; thus, sellers in this case who do not want to sell the house for a perceived loss would not want to negotiate below $\$ 195,000$. In the low price case, sellers who do not want to sell the house for a perceived loss would not want to negotiate below $\$ 185,000$. Therefore, all final negotiated prices between $\$ 185,000$ and $\$ 195,000$ would be perceived by sellers as a loss in the high purchase price case and as a gain in the low purchase price case. Hence, this "break even" constraint puts more upward pressure on the price in the high purchase price case as compared to the low purchase price case. ${ }^{11}$

To summarize, we consider four different list price strategies interacted with two variations in the seller's initial purchase price, resulting in a $4 \times 2$ experimental design. Table 1 displays the full list of parameter values used in each of the 8 different conditions. From Table 1 , we see that in all 8 conditions, the buyer's value, $v$, is held constant at $\$ 205,000 .{ }^{12}$ In addition, the seller's reservation, $r$, is always set to be $\$ 20,000$ below the list price. This ensures that the bargaining zone, which is the difference between the list price and the seller's reservation value, is constant at $\$ 20,000$ for each of the four list price conditions. Thus, by comparing negotiation behavior and the resulting negotiation outcome across the four different list price conditions, we are able to identify how the list price strategy impacts negotiations.

The only difference between the four conditions in Panels A and B is whether the seller was told that the original purchase price was high at $p_{0 h}=\$ 195,000$ or low at $p_{0 l}=\$ 185,000$. The seller's payoff does not depend on the original purchase price, so manipulating the information the seller gets regarding the original purchase price does not impact the financial incentives in any way. However, this manipulation does alter the reference point for the sellers around which they evaluate perceived gains and losses, which is its intended purpose. Therefore, by comparing negotiation behavior and outcomes across the

\footnotetext{
10 The idea that agents may behave differently based on whether outcomes are in the domain or perceived gains/losses was first introduced in Prospect Theory by Kahneman and Tversky (1979). In the model, an agent's value function is S-shaped around the reference point; it is convex in the domain of losses and concave in the domain of gains, which induces more (less) risk seeking in the domain of losses (gains). In the context of negotiations, this differential behavior can then impact counter-offers, concession behavior, and the likelihood that an agreement is reached (see Neale and Bazerman (1991) and Kahneman (1992) for a thorough discussion and a review of the literature documenting the impact of variation in the gain/loss domain on negotiations.

11 Furthermore, because buyers are not informed about the original purchase price, there is no scope for variation in this information to impact their negotiation behavior across treatments.

12 Because the buyer's value is higher than the list price, it is pareto efficient for the house to be transacted at any price between the list price and the seller's reservation value. We acknowledge that it is possible in housing negotiations for the buyer to have a value below the list price. When the buyer's value is below the list price, this scenario would likely lead to a lower final negotiated price (conditional on a transaction), across all listing price strategies. That said, the aim of our paper is to understand the relative comparison of negotiation behavior and final prices across different list price strategies. We contend that the level of the buyer's value (either above or below the list price) is unlikely to have a differential impact on negotiation behavior and final prices when comparing across the different list price strategies. As such, we choose to normalize the buyer's value to be above the list price strategy in all treatments to promote transactions and avoid negotiation impasses.
} 
Table 1

Parameter value combinations by treatment.

\begin{tabular}{|c|c|c|c|c|}
\hline List price strategy & $p_{l}$ & $v$ & $r$ & $p_{0 h}$ \\
\hline \multicolumn{5}{|c|}{ Panel A: high purchase price (domain of potential perceived losses for seller) } \\
\hline Rounded (R) & $\$ 200,000$ & $\$ 205,000$ & $\$ 180,000$ & $\$ 195,000$ \\
\hline Just Below (JB) & $\$ 199,000$ & $\$ 205,000$ & $\$ 179,000$ & $\$ 195,000$ \\
\hline Low Precise (LP) & $\$ 198,674$ & $\$ 205,000$ & $\$ 178,674$ & $\$ 195,000$ \\
\hline \multirow[t]{2}{*}{ High Precise (HP) } & $\$ 201,326$ & $\$ 205,000$ & $\$ 181,326$ & $\$ 195,000$ \\
\hline & $p_{l}$ & $v$ & $r$ & $p_{0 l}$ \\
\hline \multicolumn{5}{|c|}{ Panel B: low purchase price (domain of potential perceived gains for seller) } \\
\hline Rounded (R) & $\$ 200,000$ & $\$ 205,000$ & $\$ 180,000$ & $\$ 185,000$ \\
\hline Just Below (JB) & $\$ 199,000$ & $\$ 205,000$ & $\$ 179,000$ & $\$ 185,000$ \\
\hline Low Precise (LP) & $\$ 198,674$ & $\$ 205,000$ & $\$ 178,674$ & $\$ 185,000$ \\
\hline High Precise (HP) & $\$ 201,326$ & $\$ 205,000$ & $\$ 181,326$ & $\$ 185,000$ \\
\hline
\end{tabular}

Notes: This table summarizes the parameter values for each of the 8 treatments that comprise our experimental design. Panel A corresponds to the high purchase price condition where the initial purchase price, denoted as $p_{0 h}$, is $\$ 195,000$, while Panel B corresponds to the low purchase price condition where the initial purchase price, denoted as $p_{0 l}$, is set to $\$ 185,000$. $p_{l}$ denotes the list price and its four different values correspond to the four list price strategies we consider in the design. $v$ and $r$ denote the buyer's and seller's reservations values in each of the treatments, respectively.

conditions in Panels A and B (holding constant the list price, but varying the original purchase price), we can identify if the original purchase price impacts negotiations and to what extent this may interact with different list price strategies.

In our design, we implement known reservation values for both the buyer and seller in the negotiation process. For buyers, their reservation value is fixed at $\$ 205,000$ across all conditions, while for sellers, their reservation value is set to be $\$ 20,000$ below the list price. By implementing known reservation values in this manner, we ensure that differences in the negotiation process and outcome across different list price strategy conditions is not a result of differences in the bargaining zone. That said, this setup may not characterize the environment of real estate negations, in practice, as there is likely some uncertainty regarding the fundamental value of the house and/or biases that impact the perceived value of the house (e.g., Genesove \& Mayer, 2001; Seiler, Seiler, Harrison, \& Lane, 2013). We acknowledge that this feature has the potential to weaken the external validity of our results, as they relate to the impact of various list prices strategies. However, as we discuss in much more detail in Section 6 after presenting the main results, we contend that uncertainty in the value of the house is likely to amplify, rather than attenuate, our main findings.

We acknowledge that the negotiation process we implement in our design is stylized and may abstract away from features that are present in real house negotiations. That said, the stylized features and the controlled laboratory setting enable us to shed light on the causal effect of variation in the list price strategy on negotiations. In particular, by systematically varying and exogenously assigning the list price in the negotiation, we circumvent one possible source of bias based on the seller's attitude toward or ability in negotiating and/or selection effects based on unobserved housing quality. Lastly, implementing a controlled experiment enables us to observe all the intermediate steps of the negotiation process, and more rigorously examine how the list price strategy separately impacts the behavior of the buyer and the seller.

\subsection{Experimental procedure}

All experimental sessions were conducted in the Economics Science Laboratory (ESL) at the University of Arizona in October 2013. The experiment was computerized, and the software was programmed using z-Tree..$^{13}$ All interactions between subjects were anonymous. The subject pool consisted of undergraduate students recruited via email from an established database. We ran 8 sessions with and a total of 132 subject participants (66 negotiating pairs). In each session, subjects were randomly assigned to either the role of buyer or the role of seller and remained in this role for the entire experiment. A copy of the participant instructions can be found in the Supplementary Material.

We implemented a combination of a within and between subjects design. The manipulation of the high/low original purchase price conditions was done between groups: four sessions of the high purchase price and four sessions of the low purchase price. The manipulation of the four list price strategies was done within groups; in each experimental session, subjects participated in four separate negotiations corresponding to each of the four different list price strategy treatments. To help mitigate repeated game effects, all subjects were randomly re-matched with a different subject between each negotiation and were clearly informed of this matching protocol via the instructions.

To control for possible order effects of the within subjects manipulation of list price treatments, we used a balanced design with four different orders of the treatments. Each of the four different list price strategies appeared as the first round of negotiations in one of the orderings. ${ }^{14}$ That is, approximately $1 / 4$ of the dyads faced each of the four list price strategies the

\footnotetext{
13 We thank Urs Fischbacher (Fischbacher, 2007) for providing this software.

${ }^{14}$ With 4 different treatments, it was not practical to run 24 sessions corresponding to the 24 unique orderings of the 4 treatments. As an alternative, we ran 4 different orderings, with each treatment coming first in one of the orderings followed by a random assignment of the other 3 treatments. This resulted in the following 4 different orderings of the treatments: (i) R-JB-LP-HP, (ii) JB-LP-HP-R, (iii) LP-JB-R-HP, and (iv) HP-LP-JB-R.
} 
first round of negotiations. This balanced design enables us to test for list price treatment effects in the first round of negotiations only, without any possible confounds. At the same time, we are able to test for treatment effects in the aggregate across all four rounds of negotiations, and explore whether the treatment effects are attenuated as subjects gain experience.

After completing the four rounds of negotiations, subjects were asked to complete a short questionnaire (about $5 \mathrm{~min}$ in length). The purpose of the questionnaire was to elicit some subject-level information on demographics, experience and attitude toward negotiations, and personality traits, which we then used to explore possible heterogeneous treatment effects (more detail on the specific question is discussed in Section 4). In terms of compensation, subjects were randomly paid for one of the four rounds of negotiation. Their earnings from the selected round were then converted at a rate of 1000 $\mathrm{ECDs}=\$ 1$. In addition, all subjects received a $\$ 5$ show-up payment. On average, subjects earned a total of $\$ 17.50$, and each session lasted approximately 45 min.

\section{Results}

We proceed by presenting the aggregate data across the four different list price strategy conditions - Rounded (R), Just Below (JB), High Precise (HP), and Low Precise (LP). In presenting the results, we first consider how each of the four list price strategies separately impact various dimensions of the negotiation process. Along the way, we highlight important findings regarding the impact of the initial list price strategy on the various dimensions of the negotiation process. Lastly, we summarize our main results regarding the overall impact of the various list price strategies in relation to one another. We postpone discussion of the results until Section 6.

\subsection{The effect of original purchase price paid by the seller}

To test whether the original purchase price paid by the seller has an effect on seller behavior and the negotiation outcome (i.e., whether the sale of the house is in the perceived loss or gain domain), we compare the data across the high $(\$ 195,000)$ and low $(\$ 185,000)$ purchase price conditions. In particular, for the negotiation outcome we look at the final sale price, which is the final negotiated price, conditional on agreement between buyer and seller. To compare seller behavior, we also look at the seller's 1st counter-offer, which is the price the seller counter-offered back to the buyer (conditional on the buyer making an initial offer to the seller). Table 2 compares these two measures across the two purchase price conditions for each of the four list price strategies.

Looking first at the final sale price (Panel A of Table 2), we see that when the list price is HP, R, and JB, there are no significant differences in the final sale price between the high and low purchase price conditions $(p=.613, p=.443$, and $p=.714$, respectively). With a LP list price, the data does reveal that the final sale price is significantly higher in the high purchase price condition $(p=.045)$. However, when taken as a group, an ANOVA test does not reveal a significant effect of the initial purchase price on the final sale price $(p=.640)$.

When considering the seller's 1st counter-offer (Panel B of Table 2), a similar pattern emerges in the data. Specifically, there is no difference in the seller's 1st counter-offer when the list price is $\mathrm{HP}$, $\mathrm{R}$, or JB $(p=.374, p=.113$, and $p=.563$, respectively). But when the list price is LP, the seller's 1st counter-offer is marginally significantly higher in the high purchase price condition $(p=.075)$. Again, when examined across all list price strategies, an ANOVA test does not reveal a significant effect based on the initial purchase price $(p=.174)$. Taken together, the data reveals that the manipulation of original purchase price seems to have had little impact on seller behavior and the negotiation outcome, which is summarized below:

Observation 1: Conditional on the given list price strategy, the negotiation behavior of sellers and the final negotiation outcome are not impacted by whether the original purchase price paid by the seller is high $(\$ 195,000)$ or low $(\$ 185,000)$.

Given that there is little observed difference in the negotiation behavior of sellers or the final price based on the original purchase price, there is little reason to expect the two original purchase price conditions to differentially interact with the four list price treatments. Thus, for the remainder of the analysis, we pool the data from the high and low purchase price conditions.

\subsection{The effect of list price strategy on the negotiated outcome}

Next, we turn to the primary focus of the study - the effect of various list price strategies on the negotiated outcome. When comparing across list price strategies, we present and analyze the data from just the first round (which consists of only the subset of subjects who faced that given list price strategy in the first negotiating round), as well as the aggregate data (which consists of all subjects in the sample).

We begin by looking at the final sale price. The first two columns in Table 3 compare the average final sale price across the four list price conditions in the first round and in the aggregate. For only the first round, the average final sale price for HP, R, $\mathrm{JB}$, and LP is $\$ 193,388, \$ 189,763, \$ 187,617$, and $\$ 187,967$, respectively. An ANOVA test reveals a strong and significant effect of initial list price $(p=.012)$. More specifically, there is a strong trend where the lower the initial list price, the lower the final price; a Jonckheere-Terpstra test for ordered alternatives strongly rejects the null of equality in favor of the ordered alter- 
Table 2

The effect of the purchase price paid by seller.

\begin{tabular}{llll}
\hline Initial purchase price & List price strategy & & \\
\cline { 2 - 4 } & High Precise $(\$ 201,326)$ & Rounded $(\$ 200,000)$ & Just Below $(\$ 199,000)$ \\
\hline Panel $A-$ final sale price & & & Low Precise $(\$ 198,674)$ \\
High purchase price $(\$ 195,000)$ & 191,384 & 190,307 & 188,312 \\
Low purchase price $(\$ 185,000)$ & 191,766 & 190,125 & 189,081 \\
p-value & $(0.613)$ & $(0.443)$ & $(0.714)$ \\
Panel B - seller's 1st counter-offer & & & 187,561 \\
High purchase price $(\$ 195,000)$ & 197,574 & 196,307 & 193,873 \\
Low purchase price $(\$ 185,000)$ & 197,248 & 195,176 & 194,069 \\
p-value & $(0.374)$ & $(0.113)$ & $(0.563)$
\end{tabular}

Notes: Panel A compares the final sale price of the house across the two different initial purchase price conditions, and Panel B compares the seller's 1st counter-offer across the two different initial price conditions. Reported $p$-values are from a $t$-test of the pairwise comparison across initial purchase price conditions for a given list price strategy. All the results are robust if a Mann-Whitney $U$-test is used.

Table 3

Effect of list price strategy on final negotiated outcome.

\begin{tabular}{|c|c|c|c|c|c|c|}
\hline \multirow[t]{2}{*}{ List price strategy } & \multicolumn{2}{|c|}{ final sale price } & \multicolumn{2}{|l|}{$\%$ discount } & \multicolumn{2}{|c|}{$\%$ of surplus to seller } \\
\hline & Aggregate & First round & Aggregate & First round & Aggregate & First round \\
\hline High Precise (HP) & 191,598 & 193,388 & $4.83 \%$ & $3.94 \%$ & $43.4 \%$ & $51.0 \%$ \\
\hline Rounded (R) & 190,203 & 189,763 & $4.90 \%$ & $5.12 \%$ & $40.8 \%$ & $39.1 \%$ \\
\hline Just Below (JB) & 188,754 & 187,617 & $5.15 \%$ & $5.72 \%$ & $37.5 \%$ & $33.1 \%$ \\
\hline Low Precise (LP) & 188,490 & 187,967 & $5.13 \%$ & $5.39 \%$ & $37.3 \%$ & $35.3 \%$ \\
\hline \multicolumn{7}{|c|}{ Treatment effects ( $p$-values reported) } \\
\hline Comparison of Means & $(0.003)^{* * * *}$ & $(0.012)^{* * *}$ & $(0.863)$ & $(0.254)$ & $(0.280)$ & $(0.087)^{*}$ \\
\hline Trend Test & $(0.001)^{* * *}$ & $(0.003)^{* * * *}$ & $(0.208)$ & $(0.076)^{*}$ & $(0.039)^{* * *}$ & $(0.025)^{* * *}$ \\
\hline HP vs $R$ & $(0.428)$ & $(0.191)$ & $(0.999)$ & $(0.560)$ & $(0.894)$ & $(0.355)$ \\
\hline HP vs JB & $(0.010)^{* * *}$ & $(0.014)^{* * *}$ & $(0.895)$ & $(0.226)$ & $(0.358)$ & $(0.084)^{*}$ \\
\hline HP vs LP & $(0.005)^{* * * *}$ & $(0.026)^{* * *}$ & $(0.921)$ & $(0.416)$ & $(0.347)$ & $(0.167)$ \\
\hline R vs JB & $(0.370)$ & $(0.619)$ & $(0.942)$ & $(0.904)$ & $(0.787)$ & $(0.837)$ \\
\hline R vs LP & $(0.247)$ & $(0.749)$ & $(0.960)$ & $(0.990)$ & $(0.768)$ & $(0.953)$ \\
\hline JB vs LP & $(0.992)$ & $(0.998)$ & $(1.000)$ & $(0.984)$ & $(1.000)$ & $(0.991)$ \\
\hline
\end{tabular}

Notes: This table compares: (i) the final price, (ii) average negotiated discount (as a \% of the initial list price), and (iii) \% of the negotiated surplus to the seller, across the four list price strategies. The aggregate data comprises the data from all subjects over all four negotiating rounds, while the first round data comprises only the subset of subjects who faced the corresponding list price strategy in the first round of negotiations. Reported p-values for the comparison of means are from an ANOVA test. Reported $p$-values for the trend test are from a Jonckheere-Terpstra test. Reported $p$-values for the pairwise comparisons are corrected for multiple comparisons using the Tukey-Kramer method.

*** $p<.01$.

** $p<.05$.

* $p<.10$.

native $(p=.003$ ). For the aggregate data, a similar pattern emerges where the average final sale price for HP, R, JB, and LP is $\$ 191,598, \$ 190,203, \$ 188,754$, and 188,490 , respectively. Again, an ANOVA test reveals a significant effect of initial list price $(p=.003)$, and a Jonckheere-Terpstra test reveals a significant trend $(p=.001)$.

While the relation between list price and final sale price is interesting, it is not fully indicative of how the list price strategy affects the final sale price. To control for differences in the magnitude of the list price across the different list price strategies and to better measure how the list price strategy impacts the final price, we consider two alternative measures of the negotiation outcome. The first is the \% discount, which is the percentage difference between the list price and the final sale price. The second is the \% of surplus to seller, which is the percentage of the total available surplus (difference between buyer's reservation and seller's reservation) that went to the seller. Table 3 compares the average \% discount and \% of surplus to seller for each of the four list price strategies in the first round and in the aggregate data.

In terms of \% discount, in the first round data we see that the average \% discount for HP, R. JB, and LP is $3.94 \%, 5.12 \%, 5.72 \%$, and 5.39\%, respectively. While HP pricing results in the smallest \% discount, and JB pricing results in the largest \% discount (about 1.7\% difference), an ANOVA test does not reveal a significant effect of list price strategy $(p=.254)$, nor is there any significant pairwise effects. ${ }^{15}$ When looking at the aggregate data, the corresponding average \% discount is $4.83 \%, 4.90 \%$, $5.15 \%$, and 5.13\%, respectively. While HP pricing still yields the smallest \% discount and JB pricing yields the largest \% discount, the range of the \% discount is much smaller and, again, there is no significant main effect of list price $(p=.863)$ or any significant

\footnotetext{
$\overline{15}$ We do note that if we use a less conservative approach in our statistical analysis and do not correct for multiple comparisons in our pairwise tests, then the difference between HP and JB is significant $(p=.058)$.
} 
pairwise comparisons. The data suggests that as subjects garner more experience with this negotiation process, the effect of list price strategy on the \% discount is attenuated.

In terms of the \% of surplus to seller, the right two columns in Table 3 present the data across the four list price conditions, for the first round and in the aggregate. For the first round, the average \% of surplus to seller in HP, R, JB, and LP is 51\%, 39\%, $33 \%$, and 35\%, respectively. An ANOVA reveals a marginally significant main effect of initial list price $(p=.087)$. In addition, the pairwise comparison between HP and JB is also significant $(p=.084)$. In terms of the aggregate data, the average $\%$ of surplus to seller in HP, R, JB, and $\mathrm{LP}$ is $43 \%, 41 \%, 38 \%$, and $37 \%$, respectively. While the general pattern is similar (HP resulting in the largest \% of surplus to seller, while JB and LP are the lowest), there is no significant main effect of initial list price strategy in the aggregate data $(p=.280)$ or any significant pairwise effects on the \% of surplus to seller. ${ }^{16}$

The main findings regarding the impact of the list price strategy on the negotiated outcome are summarized in Observation 2:

Observation 2: The list price strategy appears to influence the final negotiated outcome. Specifically, we observe a significant impact of the list price strategy on the final sale price, as well as the \% of surplus that goes to the seller. Overall, the data reveals that HP pricing yields the highest final sale price, the smallest negotiated discount, and the largest \% of surplus to the seller.

\subsection{The effect of list price strategy on buyer behavior}

Because our experimental design enables us to observe the intermediate steps within the negotiation process, we are able to also analyze how the list price strategy separately impacts the negotiation behavior of buyer and seller. We first examine the negotiation behavior of buyers. The left two columns in Table 4 display the average of the buyer's initial offer (as a percentage of the list price) across the four list prices, for both the first round and the aggregate data.

In Table 4 we see that the buyer's initial offer in the first round when list prices are HP, R, JB, and LP are $90.95 \%, 80.64 \%$, $88.14 \%$, and $87.97 \%$ of the list price, respectively. An ANOVA test reveals a significant effect of initial list price $(p=.011)$. In addition, pairwise comparisons reveal that the buyer's initial offer is significantly lower when the list price is $\mathrm{R}$, compared to when it is HP, JB, and LP $(p=.010, p=.085, p=.096$, respectively. Looking at the aggregate data, Table 4 reveals that the corresponding data on buyer's initial offer across HP, R, JB, and LP are $88.29 \%, 86.54 \%, 87.06 \%$, and $88.02 \%$ of the list price, respectively. In the aggregate data, the same general pattern emerges, but the magnitude is muted; moreover, an ANOVA test on the aggregate data does not yield a significant list price effect $(p=.432)$ or any significant pairwise effects. Overall, the data from the first round suggests that buyers make the most aggressive offers with a $\mathrm{R}$ list price, but this pattern is attenuated as buyers garner some experience.

In addition to looking at the buyer's initial offer, we analyze if the list price affects the buyer's counter-offer behavior throughout the entire negotiation process. Specifically, Panel A of Fig. 1 displays the sequence of the average buyer's counter-offer (as a \% of the list price) for the first four offer/counter-offers. ${ }^{17}$ As expected, buyer counter-offers increase throughout the negotiation process across all of the list price conditions. When comparing across the different list price conditions, we observe from Fig. 1 that the effect from the list price strategy on the buyer's initial offer does not persist throughout subsequent buyer counter-offers. That is, for the 1st, 2nd, and 3rd buyer counter-offers, there are no significant pairwise differences among any of the four different list price strategies. The data appears to suggest that the list price strategy has very little persistent effect on buyer counter-offers throughout the negotiation process.

The main findings regarding how the list price strategy affects the negotiation behavior of the buyer are summarized in Observation 3:

Observation 3: The list price strategy appears impact the initial offers of buyers. Specifically, we document that R pricing leads to the most aggressive initial offers by buyers. However, $\mathrm{R}$ pricing appears to impact only the initial offer and does not persistently lead to lower buyer counter-offers in later stages of the negotiation.

\subsection{The effect of list price strategy on seller behavior}

We next examine how the list price strategy affects the negotiation behavior of the seller. The right two columns in Table 4 display the average seller's 1st counter-offer (as a percentage of the list price) made back to the buyer, for both the first round and in the aggregate data. Looking at the first round data, Table 4 reveals that the average of the seller's 1 st counter-offer when the list prices are HP, R, JB, and LP are 97.38\%, 96.39\%, 95.71\%, and 94.93\% of the list price, respectively. An ANOVA test reveals a significant effect of list price $(p=.017)$. Furthermore, a Jonckheere-Terpstra test strongly rejects the null of equality of these percentages in favor of the ordered alternative $(p=.002)$. In terms of pairwise effects, we see that the HP list price results in a higher seller's 1st counter-offer compared with both JB and LP list prices $(p=.019, p=.011$,

\footnotetext{
16 In the aggregate data, if we use a less conservative approach and look at the uncorrected pairwise comparisons of \% of surplus to seller, then the difference between HP and JB is marginally significant $(p=.098)$.

17 We analyze only the first four offer/counter-offers because there are too few observations for any meaningful analysis after the 3rd counter-offer, since most negotiations ended in an agreement by that point in the process.
} 
Table 4

Effect of list price strategy on offer behavior.

\begin{tabular}{|c|c|c|c|c|}
\hline \multirow[t]{2}{*}{ List price strategy } & \multicolumn{2}{|c|}{ buyer's initial offer (as \% of list price) } & \multicolumn{2}{|c|}{ seller's 1st counter-offer (as \% of list price) } \\
\hline & Aggregate & First round & Aggregate & First round \\
\hline High Precise (HP) & $88.29 \%$ & $90.95 \%$ & $98.15 \%$ & $97.38 \%$ \\
\hline Rounded (R) & $86.54 \%$ & $80.64 \%$ & $97.54 \%$ & $96.39 \%$ \\
\hline Just Below (JB) & $87.06 \%$ & $88.14 \%$ & $96.94 \%$ & $95.71 \%$ \\
\hline Low Precise (LP) & $88.02 \%$ & $87.97 \%$ & $96.90 \%$ & $94.63 \%$ \\
\hline \multicolumn{5}{|c|}{ Treatment effects ( $p$-values reported) } \\
\hline Comparison of Means & $(0.432)$ & $(0.011)^{* *}$ & $(0.007)^{* * * *}$ & $(0.017)^{* *}$ \\
\hline Trend Test & $(0.258)$ & $(0.897)$ & $(0.001)^{* * * *}$ & $(0.002)^{* * *}$ \\
\hline HP vs R & $(0.467)$ & $(0.010)^{* * * *}$ & $(0.491)$ & $(0.641)$ \\
\hline HP vs JB & $(0.729)$ & $(0.824)$ & $(0.019)^{* * *}$ & $(0.019)^{* *}$ \\
\hline HP vs LP & $(0.996)$ & $(0.796)$ & $(0.015)^{* * *}$ & $(0.011)^{* *}$ \\
\hline R vs JB & $(0.975)$ & $(0.085)^{*}$ & $(0.510)$ & $(0.854)$ \\
\hline R vs LP & $(0.619)$ & $(0.096)^{*}$ & $(0.457)$ & $(0.200)$ \\
\hline JB vs LP & $(0.855)$ & $(1.000)$ & $(1.000)$ & $(0.598)$ \\
\hline
\end{tabular}

Notes: This table compares the average initial offer for buyers (as a \% of the initial list price) across the four list price strategies, aggregated over both initial purchase price conditions. The aggregate data comprises the data from all subjects over all four negotiating rounds, while the first round data comprises only the subset of subjects who faced the corresponding list price strategy in the first round of negotiations. Reported $p$-values for the comparison of means are from an ANOVA test. Reported $p$-values for the trend test are from a Jonckheere-Terpstra test. Reported $p$-values for the pairwise comparisons are corrected for multiple comparisons using the Tukey-Kramer method.

*** $p<.01$.

** $p<.05$.

$p<.10$.

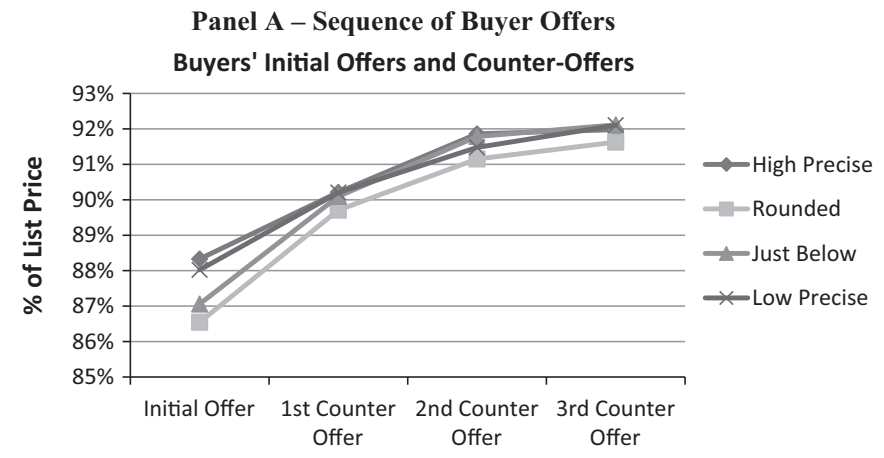

Panel B - Sequence of Seller Counter-Offers

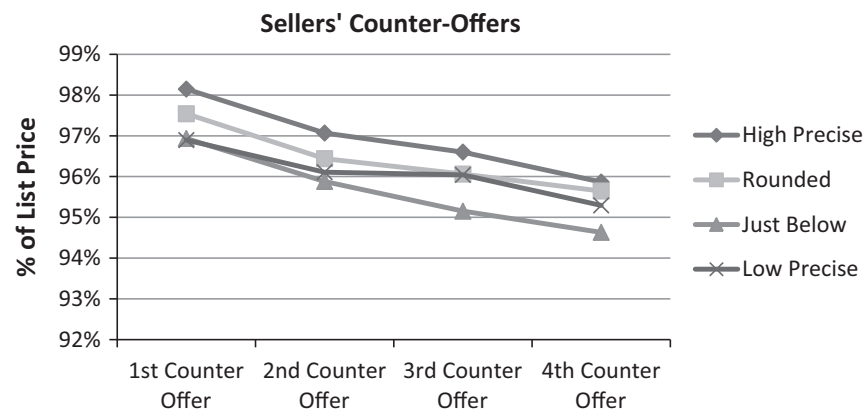

Fig. 1. Sequence of offers by list price strategy.

respectively). When looking at the seller's 1st counter-offer in the aggregate data, a similar pattern emerges as in the first round, although it is less pronounced. Namely, when comparing across the four list price strategies, an ANOVA test reveals a significant list price effect $(p=.007)$, and a Jonckheere-Terpstra test reveals a significant trend $(p=.001)$. Moreover, the HP list price continues to generate a higher seller's 1st counter-offer compared with both JB and LP list prices $(p=.019, p=.015$, respectively). 
We next consider if, and to what extent, the list price strategy has a persistent effect on the negotiation behavior of sellers throughout the negotiation process. To do so, we examine the sequence of the first four seller counter-offers across the four list price conditions. Panel B of Fig. 1 displays the relevant average data. Unlike with buyers, the list price strategy does appear to have a persistent effect of seller counter-offers throughout the negotiation process. Namely, HP pricing persistently results in the highest counter-offers, while JB pricing leads to the lowest counter-offers. In particular, the pairwise difference between HP and JB is strongly significant for the $2 \mathrm{nd}(p=.002)$, $3 \mathrm{rd}(p=.003)$, and 4 th $(p=.037)$ counter-offers made by the seller.

Unlike with buyers, when sellers make their 1st counter-offer, it is in response to the initial offer made by the buyer, and the seller's 1st counter-offer may be impacted by the buyer's initial offer. Hence, variation in the seller's 1st counter-offer may be a result of variation in the buyer's initial offer and not a response to different list price strategies. Said differently, it may be that across treatments, sellers are responding to the buyers' initial offers in a consistent way. If this were the case, we would expect to see the seller's 1st counter-offer being a consistent amount relative to the buyer's initial offer across all treatments. To investigate this possibility, we look at the effect of each list price strategy on the seller's 1st counter-offer while controlling for the buyer's initial offer. Table 5 displays the results from a regression of the seller's 1st counter-offer on dummy variables representing each of the list price strategies (with $\mathrm{R}$ being the excluded variable) and the buyer's initial offer.

The first column of Table 5 displays the output from a regression of the seller's 1 st counter-offer on dummies for each of the list price strategies without controlling for the buyer's initial offer. Consistent with the analysis above, we see a strong monotonic relation emerge; namely, HP pricing results in significantly higher 1 st counter-offers compared to $\mathrm{R}(p=.022)$, JB $(p<.001)$, and LP $(p<.001)$, while R pricing yields significantly higher 1 st counter-offers compared to JB $(p=.004)$ and LP $(p=.002)$. The second column of Table 5 displays the regression output including the buyer's initial offer as a control. We can see that the buyer's initial offer has a small but significant positive effect on the seller's 1st counter-offer; for every $\$ 1,000$ increase in the buyer's initial offer, the seller's 1st counter-offer increases by an average of $\$ 62$. However, even after controlling for the buyer's initial offer, list price strategy still significantly impacts the seller's 1st counter-offer; namely, all the coefficient estimates on the dummy variable have the same sign and similar magnitude, and remain significant.

The main findings concerning the impact of list price strategies on the negotiation behavior of the seller are summarized in Observation 4:

Observation 4: The list price strategy appears to impact the counter-offer behavior of sellers. Specifically, we document that sellers generally make the highest counter-offers when the list price is HP, and they make the lowest counter-offers when the list price is JB, even after controlling for the buyer's initial offer. Moreover, the list price strategy appears to have a persistent impact on seller counter-offers through later stages of the negotiation; HP pricing continues to result in the highest counter-offers, while JB pricing results in the lowest counter-offers.

\subsection{The effect of list price strategy on length of negotiation}

While the final price is an important dimension along which to evaluate the outcome of a negotiation, another important dimension of the negotiation process is its length. Understanding how list price strategies impact the length of the negotiations can be especially important because drawn out negotiations and delays are often costly to both parties involved. For example, from the seller's perspective, an extensive literature exists that documents the importance of mitigating "time on the market" to spare sellers carrying costs (mortgage payments, hazard insurance, etc.). A similar argument can be made that a longer negotiation process can negatively impact buyers who expend search costs, extended stays in temporary housing, and so forth. Because we observe all the intermediate steps of the negotiation process, we are able to explore the relationship between the list price strategy and the length of the negotiation. As a proxy for the length of the negotiation process, we use the total number of offers made by both the buyer and seller prior to an agreement being reached, which we denote as \# of total offers. ${ }^{18}$

Fig. 2 compares the average \# of total offers across the four list price conditions, for both the first round and the aggregate data. From Fig. 3, we see that in the first round negotiations, there is a strong relation between the list price and the \# of total offers. When the list price is HP, an average of 7.06 offers are needed to reach an agreement, while this drops to 4.50 when the price is LP. Statistically, a Kruskal-Wallis test reveals a significant effect of list price on \# of total offers ( $p=.008$ ), and a Jonckheere-Terpstra test reveals a significant trend $(p=.001)$.

As has been the case with much of the other analyses, the effect of the list price strategy on the length of negotiation is attenuated when looking at the aggregated data when subjects gain negotiation experience. Specifically, in the aggregate data, R pricing leads to the largest average \# of total offers at 8.10 , while LP pricing continues to result in the smallest \# of total offers at 7.22 (this difference is marginally significant $p=.086$ ). Although the spread within the \# of total offers is much narrower across the treatments, a Jonckheere-Terpstra test does reveal a significant trend $(p=.045)$, which provides some evidence that lower list prices do lead to shorter negotiations.

\footnotetext{
${ }^{18}$ Another measure of the length of the negotiation process would be the actual time required to reach an agreement. However, as a by-product of the experimental software, we are unable to measure time to an agreement for each negotiation pair. However, it is likely that the number of total offers needed to reach an agreement is strongly positively correlated with time since it takes time to construct counter-offers.
} 
Table 5

Regression analysis of seller's 1st counter-offer.

\begin{tabular}{lll}
\hline & \multicolumn{2}{l}{ seller's 1st counter-offer } \\
\cline { 2 - 3 } & $(1)$ & $(2)$ \\
\hline HP & $2046.77^{* * *}$ & $1713.85^{* * *}$ \\
JB & $(886.37)$ & $(879.693)$ \\
LP & $-2652.91^{* * *}$ & $-2581.25^{* * *}$ \\
buyer's initial offer & $(897.70)$ & $(882.81)$ \\
\multirow{2}{*}{ Constant } & $-2993.63^{* * * *}$ & $-2998.93^{* * *}$ \\
& $(929.39)$ & $(913.58)$ \\
& & $.062^{* * *}$ \\
& $195451^{* * *}$ & $(.022)$ \\
& $(664.78)$ & $184689.6^{* * *}$ \\
\end{tabular}

Notes: Column (1) reports the results of an OLS regression of the seller's 1st counter-offer on dummy variables for each of the list price strategies (with $R$ as the excluded variable). Column (2) reports the results of an OLS regression of the seller's 1st counter-offer on dummy variables for each of the list price strategies (with $\mathrm{R}$ as the excluded variable) and the buyer's initial offer. Standard errors are reported in parenthesis.

${ }^{* * *} p<.01$.

*** $p<.05$.

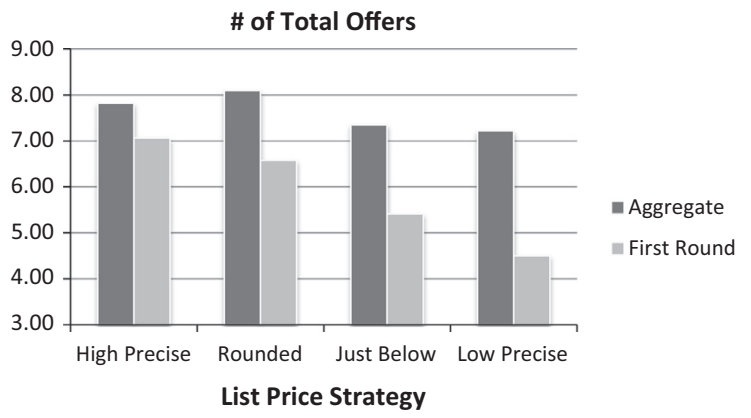

Fig. 2. Comparison of \# of total offers by list price strategy.

The main findings on how the list price strategy impacts negotiation length are summarized in Observation 5:

Observation 5: The list price strategy appears to influence the length of the negotiation process. We find that the lower the initial list price, the shorter the negotiation process (significantly fewer counter-offers are needed to reach an agreement). Namely, HP list prices result in the longest negotiations, while LP list prices result in the shortest negotiations.

\subsection{Summary of overall effect of list price strategy}

In presenting our main results, we consider how different list price strategies separately impact various dimensions of the negotiation process - the negotiated outcome, the behavior of buyers and sellers, and the length of the negotiation. We conclude this section by providing a summary of the overall impact of the various list price strategies, as they relate to one another. Specifically, we focus on the overall effect of different list price strategies for the three relevant pairwise comparisons: (i) rounded vs just below list prices, (ii) rounded vs precise list prices, and (iii) precise vs just below list prices. For brevity, in evaluating the overall impact of precise list prices, we concentrate on the high precise (HP) price rather than the low precise price (LP); we focus specifically on the HP price because, in general, that is the type of precise list price where we observe the most significant impacts on the negotiation process and negotiated outcomes. ${ }^{19}$

In comparing the R vs JB initial list price, our data reveals very little overall impact on the final negotiated outcome. Specifically, there are no significant pairwise differences in the final sale price, \% discount, or \% of surplus to seller. We do note, however, that the differences in the three outcome measures across the $\mathrm{R}$ and JB list price are in the direction of the $\mathrm{R}$ list price generating a better negotiated outcome for the seller, i.e., a higher final sale price, lower \% discount, and larger \% of surplus to seller. The only difference between the two list prices is that buyers appear to make more aggressive (lower) counter-

\footnotetext{
19 When comparing LP pricing with either R pricing or JB pricing we observer no significant differences in either of the three negotiated outcome measures we consider; thus, there does not seem to be a significantly overall differences between LP pricing and either R or JB pricing.
} 

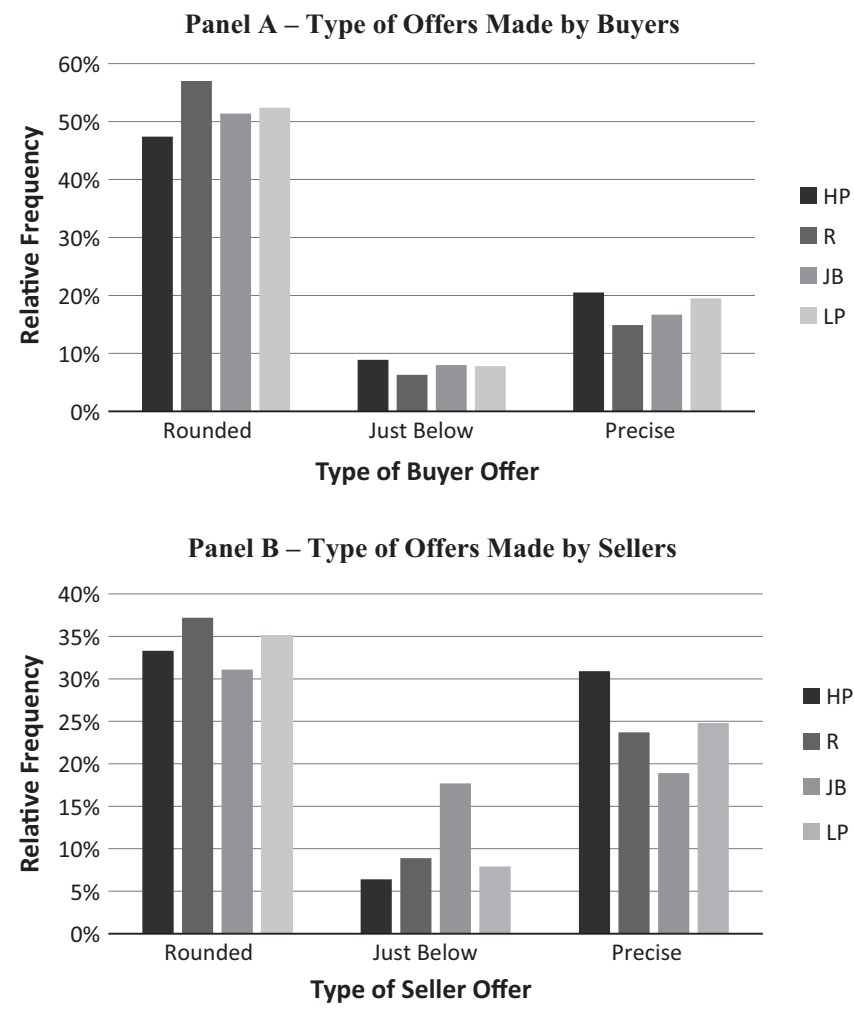

Fig. 3. Effect of list price on type of offers made.

offers with an $\mathrm{R}$ list price, although this effect does not pertain to counter-offers in later stages of the negotiation. Taken together, our results suggest that, all else equal, $\mathrm{R}$ pricing is likely not a worse pricing strategy for the seller than JB pricing.

In comparing the R vs the HP initial list price, there appears to be very few significant differences in the final negotiated outcome. Namely, neither the final sale price, \% discount, nor \% of surplus to seller are significant at standard levels. That said, the differences in these measures are in the direction of HP pricing generating a better negotiated outcome for the seller. ${ }^{20}$ In terms of the negotiation process, buyers tend to make more aggressive initial offers, but again, this does not persist in subsequent counter-offers throughout the negotiation. Overall, our data suggests that, all else equal, HP pricing is likely to generate a negotiated outcome for the seller at least as good, and possibly better, than $\mathrm{R}$ pricing.

Lastly, with regard to the comparison of the HP and JB initial list prices, our results indicate that HP pricing generates a better negotiated outcome for the seller. Specifically, HP pricing results in a significantly higher final sale price and larger \% of surplus to seller, as well as a smaller \% discount (although \% discount is not statistically significant). In terms of the negotiating process, there is little difference between these two list prices on buyer offers. However, sellers tend to make significantly higher counter-offers under the HP list price, and this persists throughout the stages of the negotiation. Our results suggest that, all else equal, HP pricing is likely to generate a superior negotiated outcome for the seller as compared to JB pricing.

\section{Additional analysis of initial list price strategy}

\subsection{Effect of list price strategy on the type of offers made}

To help shed light on how initial list price strategies impact the negotiation process, we look at the type of offers that buyers and sellers make across the four different list price conditions. In doing so, we categorize 3 different types of offers that closely parallel the categorization of types of list price strategies we implement across experimental conditions. Specifically, rounded offers are those that end in either 0000 or 5000, just below offers are those that end in either 9000 or 4000 , and precise offers are those that do not end in 000 (i.e., not rounded to the thousands digit). ${ }^{21}$

We first look at the type of offers made by buyers. For brevity, we pool the data over buyers' initial offers and 3 subsequent counter-offers. Panel A of Fig. 3 displays the relative frequency of rounded, just below, and precise offers, broken down

\footnotetext{
20 Specifically, in the first negotiating round, the HP list price generates over a $\$ 5,000$ higher list price and an increase in $12 \%$ of the surplus to the seller. Moreover, under some less conservative statistical analysis without multiple comparison corrections, both of these differences are at standard levels.

21 Note, this categorization does not span all possible list prices; namely, offers that end in 1,000, 2,000, 3,000, 6,000, 7,000, and 8,000 are taken to be neither rounded, just below, or precise. Thus, the relative frequency in each of these three categories will not sum to 1 .
} 
by the initial list price strategy. Several important observations emerge regarding the type of buyer offers. First, buyers tend to predominately make rounded initial offers, regardless of the type of initial list price. Averaged across all four list price conditions, $52 \%$ of buyer offers are rounded, while only $7.7 \%$ are just below and $18 \%$ are precise. Second, buyer offer types do not appear to be significantly impacted by the type of initial list price; a Chi-squared test reveals no significant difference in the fraction of rounded, just below, or precise offers across the four list price conditions $(p=.238, p=.771, p=.417$, respectively). ${ }^{22}$ Across the different initial list price conditions, the distributions of counter-offer types for buyers tend to be similar; thus, there appears to be no significant persistent effect of the type on initial list price on the type of buyer counter-offers.

Next we look at the type of counter-offers made by sellers. Again, for brevity we pool the first four counter-offers made by sellers. Panel B of Fig. 3 displays the relative frequency of rounded, just below, and precise counter-offers, broken down by the initial list price strategy. Unlike the buyers, sellers do not appear to be predominately making rounded offers throughout the negotiation process. Specifically, the overall percentage of offer types, pooled over all four initial list price conditions, is $34 \%$ rounded, $10 \%$ just below, and $25 \%$ precise. ${ }^{23}$ Looking across the different initial list price conditions, a Chi-squared test reveals no significant difference in the proportion of rounded counter-offers $(p=.694)$. However, looking at just below counter-offers, we see from Fig. 3 that sellers in the JB condition are significantly more likely to make just below counteroffers throughout the negotiation $(p=.002)$. Similarly, when looking at precise offers, sellers in the HP condition are significantly more likely to make precise counter-offers throughout the negotiation $(p=.067)$. To summarize, the data suggests that sellers tend to use rounded and precise counter-offers in roughly equal proportion. Moreover, just below and precise initial list prices seem to have a persistent influence on sellers, as sellers make significantly more just below counter-offers when the list price is just below, and they make significantly more precise counter-offers when the list price is precise.

\subsection{The effect of gender}

We now explore if, and to what extent, the gender of the negotiating parties may play a role in mediating the main treatment effects of list price strategy on negotiation behavior. ${ }^{24}$ Panel A of Fig. 4 segments the buyer's initial offer by gender. The result is a similar "U-shaped" pattern for both male and female buyers. Namely, the buyer's initial offer is relatively higher when the price is HP, drops to its lowest level when the price is $R$, and then increases again when the price is JB and LP. An ANOVA test does not reveal a significant effect of gender $(p=.144)$. However, this effect is more pronounced in males, and appears to be driven by the fact that males react more than females when the list price is LP, in the form of significantly higher initial offers $(p=.064)$.

With regard to possible gender differences for sellers, Panel B of Fig. 4 compares the seller's 1st counter-offer, segmented by list price and gender. For sellers, an ANOVA test reveals a significant effect of gender $(p=.001)$. Similar to buyer behavior, this seems to be primarily driven by the differential responses by male and female sellers to the LP list price. Compared to JB pricing, male sellers increase their 1st counter-offer when the list price is LP, while female sellers decrease their 1st counter-offer. Furthermore, male sellers' 1 st counter-offer with a LP list price is $2 \%$ higher than that of female sellers, and this difference is significantly higher $(p=.004)$.

Taken together, the data suggests that in response to the different list price strategies, male and female buyers exhibit a similar pattern of initial offers, with males making marginally higher initial offers when the list price is LP. Although, male and female sellers exhibit a partially differential response to the LP list price strategy, with males making significantly higher counter-offers when the list price is LP (in the roles of both buyer and seller).

\subsection{The effect of prior negotiating experience}

It is likely that subjects come to the experiment with differing levels of prior negotiating experience. This level of experience may impact how subjects react to the various list price strategies. To explore this possibility, we collected information on each subject's prior negotiating experience via a post-experiment questionnaire. The question we use to construct our measure of negotiating experience asks subjects to report how many times in the last year they purchased an item where

\footnotetext{
${ }^{22}$ We do note, however, that there is some marginal evidence that the initial list price strategy influences the type of initial offer made by the buyer. In particular, buyers tend to be relatively more likely to make an initial offer of the same type as the initial list price. If we consider just the initial offer, then buyers in the $\mathrm{R}$ condition have the highest percentage of rounded initial offers ( $73 \%$ in R condition vs $63 \%$ pooled over HP, JB, and LP; $p=.110$ ). In the JB condition, buyers have the highest percentage of just below initial offers ( $8 \%$ in JB condition vs $3 \%$ pooled over HP, R, and LP; $p=.106$ ). In the HP and LP conditions buyers have the highest percentage of precise initial offers (21\% pooled over HP and LP conditions vs $9 \%$ pooled over R and JB; $p=.009$ ). Thus, there appears to be some initial anchoring powering of the type of initial list price of buyers, as buyers tend to be relatively more likely to make the same type of initial offer as the type of initial list price.

${ }^{23}$ If we just look at the initial 1 st counter-offers made by sellers, then the percentage of rounded offers is higher at approximately $42 \%$, while the percentage of precise offers is $17 \%$. However, from the 2 nd counter-offer onward, the percentage of rounded and precise offers are roughly equal at approximately $30 \%$ each. Thus, there may be some initial tendency for sellers to use a rounded 1st counter-offer, but throughout the entire negotiation process, sellers do not appear to be using rounded counter-offers at much higher rates, as is the case with buyers.

${ }^{24}$ We focus on possible gender difference for two main reasons. Firstly, it is easily observable in the lab. Secondly, and more importantly, a mature body of literature has documented gender differences in negotiations. In lieu of citing individual studies, we refer interested readers to the following studies that provide comprehensive, although not exhaustive, views of the literature: Seagraves and Gallimore (2013) who discuss the role of gender specifically in real estate negotiations, Walters, Stuhlmacher, and Meyer (1998), Kray and Thompson (2004), and Bowles, Babcock, and Lai (2007) who discuss gender differences in negotiations more generally, and Croson and Gneezy (2009), and Niederle and Vesterlund (2011) who review the role of gender in competition.
} 


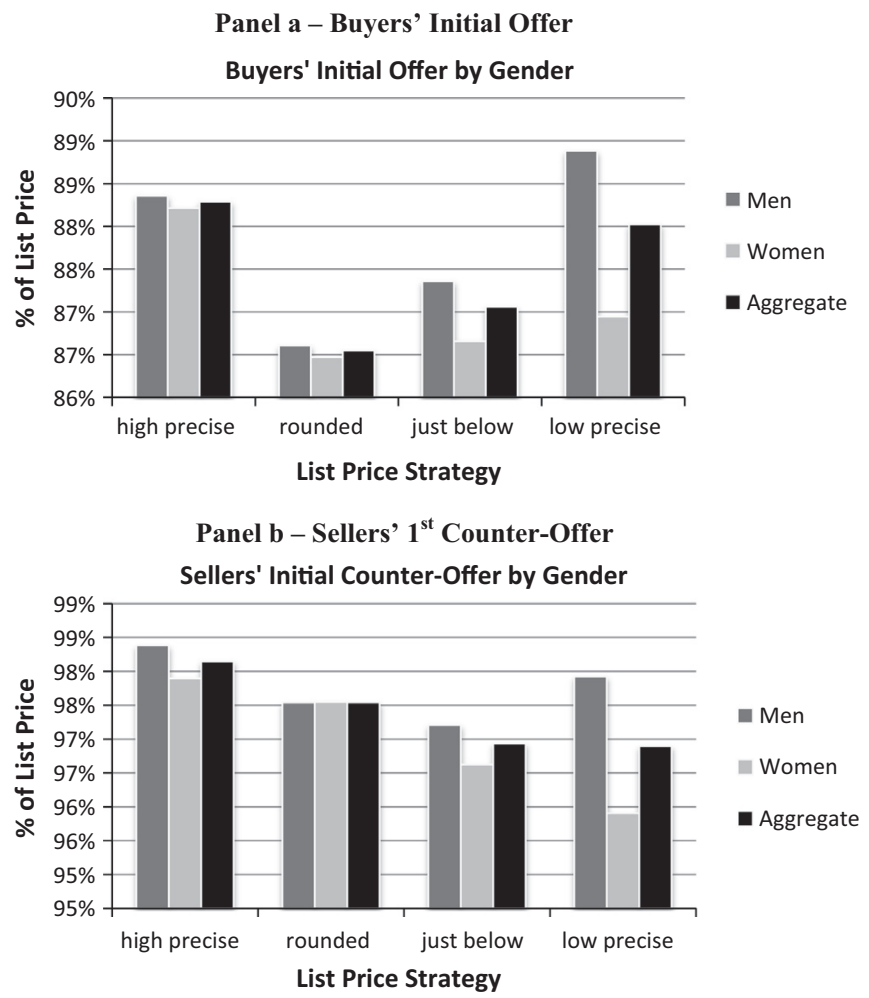

Fig. 4. Offers by gender and list price.

they negotiated the final price. We then stratify the sample into two groups based on their answer: (i) low experience - those subjects who reported having purchased zero goods where they negotiated the price, and (ii) high experience - those subjects who reported having purchased five or more items where they negotiated the price. ${ }^{25}$

Looking first at buyer behavior, Panel A of Fig. 5 compares the buyer's initial offer across the list price strategies, parsed by negotiating experience. As one might expect, Fig. 5 shows that prior negotiating experience attenuates the effect of the list price strategy. In particular, buyers with more experience show much less variation in their initial offers in response to the different list prices. This effect is the most pronounced when comparing the initial offer associated with the list prices HP and R. Low experience subjects offer $88.75 \%$ when the list price is HP and $85.12 \%$ when the list price is $\mathrm{R}$, while the corresponding values for the high experience buyers are $86.88 \%$ and $86.12 \%$, respectively. Thus, the data suggests that buyers with less experience are likely to react more, by making a lower initial offer when facing an $\mathrm{R}$ list price.

Looking next at seller behavior, Panel B of Fig. 5 compares the seller's 1st counter-offer across the list price strategies, segmented by negotiating experience. Consistent with expectations, sellers with more negotiating experience display much less reaction in their 1st counter-offers, and make more aggressive 1st counter-offers, regardless of the list price strategy. However, for both low and high experience sellers, a consistent pattern emerges in the effect of the list price; namely, lower list prices tend to result in lower 1st counter-offers by the seller, a response that is stronger for the less experienced sellers.

The general findings regarding the effect of prior negotiation experience by the negotiating parties on the impact of list prices and negotiation behavior is summarized as follows: For both buyers and sellers, higher levels of prior negotiating experience attenuates, but does not eliminate, the effect list price strategies have on initial offers and counter-offers.

\section{Discussion}

When examining the effect of list price strategy on final sale price, our results indicate that HP pricing tends to lead to the highest final prices, the largest fraction of the surplus to sellers, and the smallest negotiated discount, especially in comparison to JB pricing. With regard to the negotiated discount, although our results are not significant at standard levels, the

\footnotetext{
${ }^{25}$ This stratification roughly results in the low experience subjects representing the lowest tercile and the high experience subjects representing the highest tercile. If we instead stratify the sample based on the median, the results are qualitatively similar, although not quantitatively as robust. In addition, we also asked subjects whether they had purchased an item on Craigslist (a secondary market website where transactions are most often negotiated at the time of sale), and a question regarding whether they had ever purchased a car (another asset where negotiation is common). If we stratify the sample into low and high experience based on whether they answered affirmatively to either of these questions, the results are also qualitatively very similar.
} 

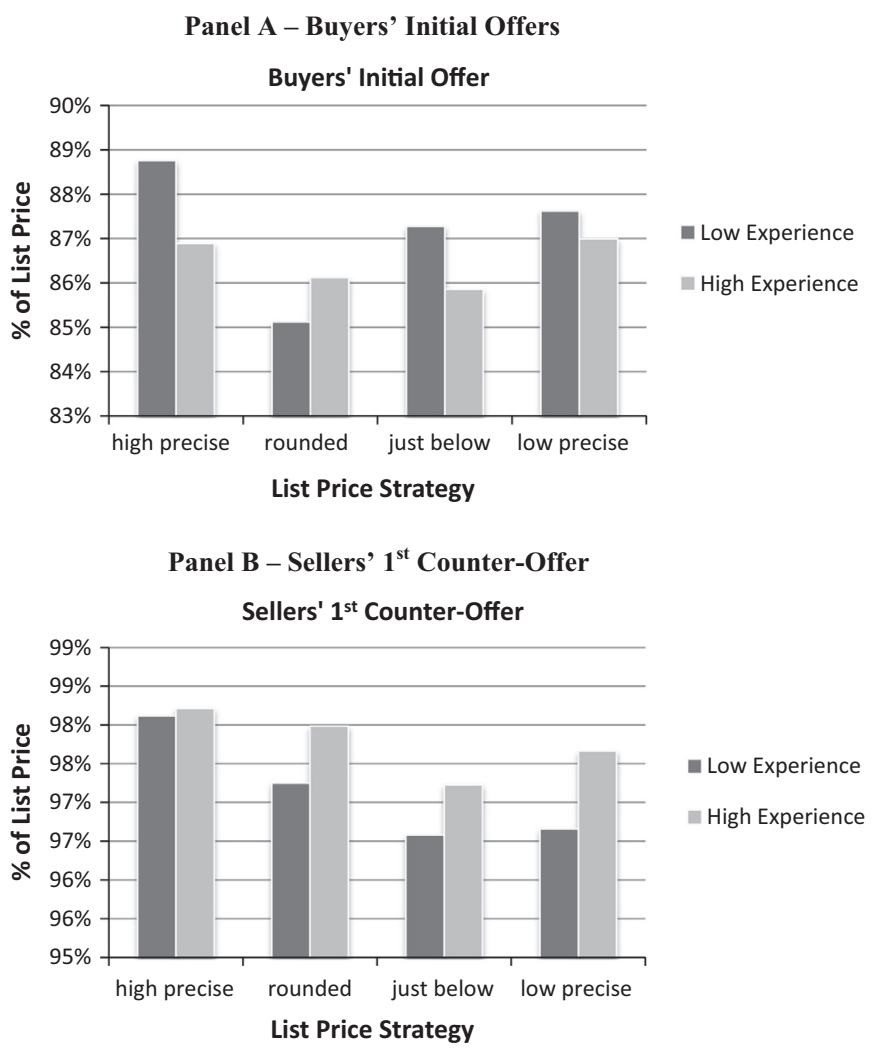

Fig. 5. Offers by negotiation experience and list price.

observed 3.94\% negotiated discount with HP pricing and 5.72\% discount with JB pricing is consistent, both in terms of direction and magnitude of the difference, with those found in Beracha and Seiler (2014), who use empirical transactions data. From the seller's perspective, we find that HP pricing leads to the highest final sale price. This finding differs from Beracha and Seiler (2014), who conclude that JB pricing leads to the highest final prices. While there appears to be an inconsistency in the findings across the studies, the differing results can be reconciled when taking into account the role of housing values. Specifically, in our design there is no variation in home values; thus, higher final sale prices associated with HP pricing follow from the fact that the HP list price is the highest and HP pricing leads to the smallest negotiated discounts. However, in the transactions data used by Beracha and Seiler, the authors find that JB pricing is associated with the greatest degree of over-pricing. Hence, this over-pricing outweighs the larger negotiated discounts associated with JB pricing, which nets greater proceeds for the seller. Our findings suggest the list price strategy that maximizes the seller's net proceeds will depend on the extent of over-pricing associated with JB pricing. JB pricing will be preferred by the seller when the property is over-priced, whereas HP pricing will be optimal when the list price is set closer to the true value.

We also note that, while not directly comparable because of how precise and rounded prices are defined, the magnitude and direction of our results regarding the impact of list price strategy are also generally consistent with the transactionsbased results reported in Janiszewski and Uy (2008) and Thomas et al. (2010). ${ }^{26}$ Specifically, Janiszewski and Uy document an approximately $1.5 \%$ larger negotiated discount for more rounded list prices (prices rounded to the thousands digit) compared to more precise list prices (those rounded to the hundreds digit). Similarly, Thomas et al. find that prices with fewer than three ending zeros result in a .2\% higher final sale price, and that each additional ending zero is estimated to reduce the final sale price by approximately $.09 \%$.

Because of our ability to observe all the intermediate steps within the negotiation process, we are able to identify how the list price strategy separately impacts the negotiation behavior of buyers and sellers, which allows us to shed light on why different list price strategies may impact the negotiated outcome. We find that buyers and sellers appear to be differentially impacted by the list price strategy. Specifically, buyers are impacted the most by R pricing, in the form of making significantly lower initial offers; however, as the negotiation process continues, the list price does not have a persistent impact on subsequent buyer counter-offers. We suspect this is in large part a result of the type of counter-offers made by sellers.

\footnotetext{
${ }^{26}$ Our results regarding the general pattern between list price strategy and final sale price are also generally consistent with the experimental results of Mason et al. (2013), who consider a different context than real estate. Namely, the authors find that more precise initial buyer offers (most of which in their sample were precise to the ones digit) lead to higher final sale prices in a simulated dyadic negotiation over a used car, compared to rounded initial offers (most of which were) only precise to the thousands digit.
} 
Across list price conditions, we do not observe substantial variation in the distribution of seller counter-offer types (in general, seller counter-offers tend to be roughly $30-35 \%$ rounded, $10-15 \%$ just below, and $20-25 \%$ precise). If buyers are adjusting or reacting to the seller's preceding counter-offer, then the list price likely becomes of second-order influence, compared to the more salient, preceding seller counter-offer. Thus, a plausible explanation for why subsequent buyer counter-offers (after the initial offer) are not differentially impacted by the type of initial list price strategy is the lack of substantial variation in the types of seller counter-offers across the different list price strategy conditions.

Sellers, on the other hand, are most impacted by HP and JB pricing, in the form of making higher initial counter-offers with HP pricing and lower initial counter-offers with JB pricing. Furthermore, this effect persists in subsequent counteroffers by the seller throughout the negotiation process. We do observe that the type of initial list price does influence the type of counter-offers sellers make throughout the negotiation process. Specifically, sellers make significantly more just below counter-offers when the list price is just below, and they make more precise counter-offers when the list price is precise (especially high precise). Taken together, the main differences in the negotiated outcomes across the list price strategy conditions (i.e., the smallest negotiated discount in the HP condition and the largest discount in the JB condition) are likely attributed, in large part, to changes in the negotiation behavior of sellers. Namely, sellers persistently make relatively higher counter-offers and more precise counter-offers throughout the negotiation process in the HP condition, while they make relatively lower counter-offers and more just below counter offers in the JB condition.

Another pattern that emerges from our data is the difference between HP and LP list pricing. Most notably, we find that HP pricing leads to a significantly higher final sale price, compared to LP pricing. Our results suggest that the position of the precise price may matter. Conditional on the seller choosing a precise price, setting a precise price that falls just above the corresponding rounded price may yield a higher price than choosing a precise price just below the rounded price. However, we also find that LP pricing results in significantly shorter negotiations (in terms of number of offers needed to reach an agreement), compared to HP pricing. Thus, sellers who are concerned about prolonging time-on-the-market may opt for a LP list price because the benefit of a quicker negotiation with the buyer may outweigh the disadvantage of a lower final sale price.

Throughout the analysis, a consistent result is that any observed effects of the list price strategy in the first negotiation round data are attenuated in the aggregate data across all negotiating rounds. Alternatively stated, as buyers and sellers gain negotiating experience, the impact of the list price strategy is weakened. This muting effect is further confirmed when we incorporate self-reported measures of negotiating experience. Namely, when we stratify buyers and sellers based on their negotiating experience in other markets, we observe that buyers and sellers who report being more experienced negotiators show less variation in their counter-offers to the various list prices. That said, while negotiating experience did mitigate the impact of list price strategy, it did not eliminate it. An important implication of this result is that we may expect the effect of list price strategy to be stronger in real estate transactions by individuals, where the negotiating parties are likely to have less experience. Yet, even when the transaction is being brokered by experienced real estate agents, list price strategy may still impact the negotiation process, although to a lesser extent.

We conclude this section by discussing a few of the stylized features of our experimental design and how these features relate to the main results we document. First, across the four different list price conditions, the seller's reservation value changed proportionally to the magnitude of the list price amount (resulting in the seller's reservation always being $\$ 20,000$ below the list price). There is some concern that this variation in the seller's reservation value could be driving our main results, rather than the list price strategy. In particular, it has been previously shown that, in negotiations, agents adopt their reservation as their reference point (Kristensen \& Gärling, 1997a; White et al., 1994). Moreover, changes in a negotiating party's reference point have been posited to impact whether, and the extent to which, negotiating parties perceive the anchor point (i.e., the list price) as a gain or loss (Kristensen \& Gärling, 1997b, 2000). As a result, changes in a negotiating party's reference point can indirectly impact negotiations by impacting how the anchor point is perceived and the subsequent adjustment from the anchor point (Kristensen \& Gärling, 1997b, 2000) via the oft-implemented anchor-andadjustment process (e.g., Northcraft \& Neale, 1987). Therefore, in our design, changes in the seller's reservation value across listing price conditions can change the seller's reference point, which can possibly impact his/her negotiation behavior and the outcome. However, the seller's reservation is always $\$ 20,000$ below the list price, indicating that sellers would view the list price in the domain of gains across all list prices and, further, the magnitude of this gain is constant. Therefore, given that the position of the seller's reservation - the reference point - relative to the initial list price - the anchor - is unchanged across our four list price conditions, we contend that it is unlikely that the variation in the seller's reservation explains all of the variation in seller behavior and negotiated outcomes, at least through an indirect channel by which reservation values have been suggested in the literature to influence the negotiation process. Furthermore, because the seller's reservation was private information, variation in the seller's reservation should have had no direct effect on variation in buyer behavior across the different list price conditions. ${ }^{27}$ That said, we certainly cannot rule out the possibility that variation in the seller's reservation had some other, non-negligible, direct influence on the negotiation process.

\footnotetext{
27 It is worth noting that even though the buyer's reservation did not change, the position of the buyer's reservation did change, relative to the list price, across treatments. As such, it is possible that variation in buyer behavior across list price conditions could have been impacted by different perceptions of the list price. Recall that for buyers the biggest effect we find is that buyers made significantly lower initial offers under R pricing, relative to HP pricing. Given that the R price was lower than the HP price, the R price would have been perceived as more of a gain to the buyer. In line with Kristensen and Gärling (1997b, 2000), R pricing would then be predicted to result in higher offers from buyers, which is in opposition to our finding. Thus, it seems unlikely that variations in the buyer's reservation relative to the list price accounted to for the variation in buyer behavior that we observe across list price conditions.
} 
Another stylized feature of our design is that we implement known reservation values for the buyer and seller, which we acknowledged in Section 3.1 is likely to be an abstraction from real-estate negotiations in practice. This feature certainly has the possibility to cast some doubt on the external validity of our results. That said, there is a strong possibility that unknown values may amplify, rather than attenuate, the main effects we document. Mason et al. (2013) discuss how, in the presence of uncertainty, more precise anchors (i.e., the list price in our setting) can be more potent, as they will be perceived by the negotiating counter-party as being more informed and reasoned; consequently, this will result in less adjustment away from more precise anchors, which the authors document in their study. Our data suggests that high precise list prices result in higher final prices and less adjustment from the list price, compared to the just below list price. Based on the arguments put forth by Mason et al. (2013), it is quite plausible that with unknown values, the adjustment from the high precise list price would be relatively smaller as compared to the just below list price, thus magnifying the effect we document. A similar argument could also be made when looking at buyers' initial offers, where we document that buyers made higher offers (i.e., less adjustment) with a high precise price as compared to the rounded price. In addition, as discussed earlier, many of our documented results are generally consistent with the prior transactions-based, empirical studies, where there is likely to be some uncertainty regarding housing values.

\section{Conclusion}

Buying a home is one of the most financially significant transactions a person will ever make. One of the key decisions involved in selling a house is choosing the initial list price. Given the order of magnitude of house prices, even small percentage changes in the final sale price can translate into sizable absolute dollar amounts. Therefore, it is important for the seller to choose a list price that will maximize the final sale price. To this end, it is imperative to first understand how listing price strategies impact the negotiation process and, ultimately, the outcome of the negotiation. The main motivation of this study is to use an innovative experimental approach to investigate the effect of three commonly implemented list price strategies Rounded, Just Below, and Precise - on housing negotiations. Within the experiment, subjects engage in a stylized, bi-lateral housing negotiation where we systematically vary the initial list price strategy across treatments, while holding the other features of the negotiating process constant. This enables us to identify the effect of these list price strategies on the offer behavior of buyers and sellers as well as on the negotiated outcome.

Our results indicate that the list price strategy can directly impact the negotiations. In terms of the negotiation outcome, we find that a high precise list price (a precise price that is above a rounded price) results in the highest final sale price and the largest share of the surplus going to the seller. In terms of the negotiated discount, we find that high precise pricing leads to the smallest discount, while just below pricing leads to the largest discount. With regards to the negotiation behavior, our results indicate that the list price strategy impacts buyers and sellers differently. Buyers make the lowest initial offer when facing a rounded list price, but this effect dissipates in subsequent counter-offers in later stages in the negotiation. For sellers, high precise pricing leads to the highest counter-offers and an increased frequency of precise counter-offers, while just below pricing results in the lowest counter-offers and an increased frequency of just below counter-offers (and this is robust to controlling for the buyer's initial offer). Moreover, these patterns of counter-offer behavior exhibited by sellers persists throughout later stages of the negotiation process; this persistent effect of initial list price strategy on seller counter-offer behavior appears to be the primary mechanism through which the initial list price strategy impacts the final negotiation outcome. Lastly, we find that negotiating experience tends to attenuate the above-mentioned effects of the list price strategy, although it does not always eliminate the effect entirely.

Our paper is not the first to examine the question of how list prices impact real estate transactions. Instead, we are the first to explore the question of how list prices affect the real estate negotiation process. By implementing a controlled experiment, our approach benefits from the ability to draw causal inference regarding the effect of list price strategies on real estate negotiations, while circumventing several plausible sources of bias associated with inferences drawn from transactions-based data (e.g., systematic selection of the list price strategy based on the seller's negotiating style/ability and/or unobservable housing quality). Therefore, we view this study as an important and necessary complement to the extant empirical literature aimed at advancing our understanding of how list prices impact real estate negotiations. In this paper, our new experimental results, along with the prior empirical findings (see Allen \& Dare, 2004, 2006; Beracha \& Seiler, 2014; Janiszewski \& Uy, 2008; Palmon et al., 2004; Thomas et al., 2010), combine to provide a clearer and more robust understanding of how list price strategies impact the real estate negotiation process.

We document evidence that the type of initial list price can impact the buyer's initial offer, especially when the price is rounded. This finding gives rise to an important consideration; namely, what information is possibly conveyed to buyers through the type of list price. Several possibilities have been established in prior research. More precise list prices may signal to the buyer that the seller is less flexible in the negotiations (Allen \& Dare, 2006; Mason et al., 2013; Thomas \& Park, 2014). More precise list prices may signal that the house is of higher quality (Beracha \& Seiler, 2014). More precise prices may also signal to the buyer that the seller is more reasoned and informed about the price (Mason et al., 2013), which could influence the buyer's perception of the seller's reservation value. Lastly, more precise list prices might evoke some uncertainty on the side of buyers, which then will lead them to perceive more precise prices as being lower (Thomas et al., 2010). In our design, we abstract away from uncertain housing quality and uncertain housing values, so there is no mechanism to signal these attributes through the list price. As a result, we posit that the higher initial offers observed in our data when the list price 
is more precise are likely attributed to some perceived initial signal of negotiating inflexibility by the seller and/or a lower perception of the price.

Overall, our experimental results indicate that a high precise price (a precise price just over the corresponding rounded price) results in the least aggressive initial offer from buyers and ultimately, the best negotiated outcome for the seller - the largest final price, smallest negotiated discount, and largest percentage of the surplus. Our results, combined with those of Thomas et al. (2010) who document that buyers perceive more precise prices to be lower, suggest that sellers ought to set high precise list prices. However, data from prior studies suggests that most list prices tend to be clustered on prices rounded (to at least) the thousands digit (i.e., ending in at least three zeros). This raises the important question of why sellers, in practice, tend to shy away from a precise price. Prior research offers some plausible explanations as to why sellers may set more rounded prices including: (i) increasing visibility based on buyer search patterns (Allen \& Dare, 2006; Seiler, Madhavan, \& Liechty, 2012); (ii) signaling more flexibility on the price (Allen \& Dare, 2006; Mason et al., 2013; Thomas \& Park, 2014), which may attract buyers and lead to a better negotiated outcome (Medvec \& Galinsky, 2005); (iii) signaling information about the value of the home; (iv) attempting to appeal to more "focal" prices (Pope et al., 2014); (v) not irritating buyers who may view precise list prices as "a manipulative gambit or obnoxious ploy" (Mason et al., 2013); or (vi) attempting to evoke more certainty from a buyer regarding the price (Thomas et al., 2010).

In this paper, we focus very specifically on causally identifying how various initial list price strategies directly impact negotiation behavior and the resulting negotiated outcome. Our results suggest that the type of list price can impact several aspects of real estate negotiations including the final sale price, the magnitude of the negotiated discount, and the length of the negotiation process. That said, selling a house is a complex transaction and when selecting a list price strategy, sellers (or their agents) may be basing their decisions on many additional factors and motivations other than on how the list price will affect the final price directly, as discussed above. While beyond the scope of the current study, the issue of how various list price strategies indirectly affect housing transactions by interacting with these other factors is important and certainly warrants future research. In addition, while we consider only the impact of initial list price strategies, it would be interesting to explore if, and to what extent, different types of counter-offer strategies made by buyers and sellers impact the negotiation process through the anchor and adjustment process.

\section{Acknowledgements}

We thank Xudong An, Marlon Boarnet, Dennis Capozza, Laura Cardella, Thomas Davidoff, Mike Eriksen, Jeff Fisher, Donald Haurin, Patrick Hendershott, Christian Hilber, David Ling, Steve Malpezzi, Norm Miller, Bill Mundy, Patrick Smith, Jon Wiley, Jeff Zabel, and Alan Ziobrowski for valuable discussions and contributions. All errors remain our own.

\section{Appendix A. Supplementary material}

Supplementary data associated with this article can be found, in the online version, at http://dx.doi.org/10.1016/j.joep. 2015.11.001.

\section{References}

Allen, M., \& Dare, W. (2004). The effects of charm listing prices on house transaction prices, Real Estate Economics, 32, 695-713.

Allen, M., \& Dare, W. (2006). Charm pricing as a signal of listing price precision. Journal of Housing Research, $15,113$.

Anderson, E., \& Simester, D. (2003). Effects of \$9 price endings on retail sales: Evidence from field experiments. Quantitative Marketing and Economics, 1, 93-110.

Anenberg, E., \& Laufer, S. (2014). Using data on seller behavior to forecast short-run house price changes. FEDS working paper no. 2014-16. Washington, DC: Board of Governors of the Federal Reserve System.

Anenberg, E., \& Kung, E. (2014). Estimates of the size and source of price declines due to nearby foreclosures. American Economic Review, 104, $2527-2551$.

Anglin, P., Rutherford, R., \& Springer, T. (2003). The trade-off between the selling price of residential properties and time-on-the-market: The impact of price setting. Journal of Real Estate Finance and Economics, 26, 95-111.

Arnold, M., \& Lippman, S. (1998). Posted prices versus bargaining in markets with asymmetric information. Economic Inquiry, $36,450-457$.

Basu, K. (1997). Why are so many goods priced to end in nine? And why this practice hurts the producers? Economics Letters, 53, 41-44.

Basu, K. (2006). Consumer cognition and pricing in the nines in oligopolistic markets. Journal of Economics E Management Strategy, 15, 125-141.

Beracha, E., \& Seiler, M. (2014). The effect of listing price strategy on transaction selling prices. Journal of Real Estate Finance and Economics, 49, $237-255$.

Bester, H. (1993). Bargaining versus price competition in markets with quality uncertainty. American Economic Review, 83, $278-288$.

Bester, H. (1994). Price commitment in search markets. Journal of Economic Behavior E Organization, 25, 109-120.

Bizer, G., \& Schindler, R. (2005). Direct evidence of ending-digit drop-off in price information processing. Psychology \& Marketing, 22, 771-783.

Bowles, H., Babcock, L., \& Lai, L. (2007). Social incentives for gender differences in the propensity to initiate negotiations: Sometimes it does hurt to ask. Organizational Behavior and Human Decision Processes, 103, 84-103.

Chetty, R., Looney, A., \& Kroft, K. (2009). Salience and taxation: Theory and evidence. American Economic Review, 99, $1145-1177$.

Croson, R., \& Gneezy, U. (2009). Gender differences in preferences. Journal of Economic Literature, 47, 448-474.

DellaVigna, S. (2009). Psychology and economics: Evidence from the field. Journal of Economic Literature, 47, $315-372$.

Desai, P., \& Purohit, D. (2004). "Let me talk to my manager": Haggling in a competitive environment. Marketing Science, 23, 219-233.

Engelhardt, G. V. (2003). Nominal loss aversion, housing equity constraints, and household mobility: Evidence from the United States. Journal of Urban Economics, 53, 171-195.

Evans, J., \& Berman, B. (1997). Marketing. NJ: Prentice Hall.

Finkelstein, A. (2009). E-ztax: Tax salience and tax rates. The Quarterly Journal of Economics, 124, 969-1010.

Fischbacher, U. (2007). z-Tree: Zurich toolbox for ready-made economic experiments. Experimental Economics, 10, 171-178. 
Friedman, L. (1967). Psychological pricing in the food industry. In A. Phillips \& O. E. Williamson (Eds.), Prices: Issues in theory, practice, and public policy (pp. 187-201). Philadelphia: University of Pennsylvania Press.

Gedenk, K., \& Sattler, H. (1999). The impact of price thresholds on profit contribution-Should retailers set 9-ending prices? Journal of Retailing, 75, 33-57. Gendall, P., Holdershaw, J., \& Garland, R. (1997). The effect of odd pricing on demand. European Journal of Marketing, 31, 799-813.

Genesove, D., \& Mayer, C. (2001). Loss aversion and seller behavior: Evidence from the housing market. Quarterly Journal of Economics, 116, 1233-1260.

Gill, D., \& Thanassoulis, J. (2015). Competition in posted prices with stochastic discounts. The Economic Journal. http://dx.doi.org/10.1111/ecoj.12294 (accepted for publication).

Gill, D., \& Thanassoulis, J. (2009). The impact of bargaining on markets with price takers: Too many bargainers spoil the broth. European Economic Review, 53, 658-674.

Han, L., \& Strange, W. (2014). What is the role of the asking price for a house? University of Toronto working paper.

Haurin, D., Haurin, J., Nadauld, T., \& Sanders, A. (2010). List prices, sale prices, and marketing time: An application to U.S. housing markets. Real Estate Economics, 38, 659-685.

Haurin, D., McGreal, S., Adair, A., Brown, L., \& Webb, J. (2013). List price and sales prices of residential properties during booms and busts. Journal of Housing Economics, 22, 1-10.

Holdershaw, J., Gendall, P., \& Garland, R. (1997). The widespread use of odd pricing in the retail sector. Marketing Bulletin, 8, 53-58.

Janiszewski, C., \& Uy, D. (2008). Precision of the anchor influences the amount of adjustment. Psychological Science, 19, 121-127.

Kahneman, D. (1992). Reference points, anchors, norms, and mixed feelings. Organizational Behavior and Human Decision Processes, 51, $296-312$.

Kahneman, D., \& Tversky, A. (1979). Prospect theory: An analysis of decision under risk. Econometrica, 47, 263-291.

Kalyanam, K., \& Shively, T. (1998). Estimating irregular pricing effects: A stochastic spline regression approach. Journal of Marketing Research, 35, 16-29.

Kassaye, W. (1990). The role of haggling in marketing: An examination of buyer behavior. Journal of Consumer Marketing, 7, 53-62.

Knight, J. (2002). Listing price, time on market, and ultimate selling price: Causes and effects of listing price changes. Real Estate Economics, 30, $213-237$.

Korvorst, M., \& Damian, M. (2008). The differential influence of decades and units on multidigit number comparison. The Quarterly Journal of Experimental Psychology, 61, 1250-1264.

Kray, L., \& Thompson, L. (2004). Gender stereotypes and negotiation performance: An examination of theory and research. In B. Staw \& R. Kramer (Eds.). Research in organizational behavior (Vol. 26, pp. 103-183). Oxford: Elsevier Ltd..

Kreul, L. (1982). Magic numbers: Psychological aspects of menu pricing. Cornell Hotel and Restaurant Administration Quarterly, $23,70-75$.

Kristensen, H., \& Gärling, T. (1997a). Determinants of buyers' aspiration and reservation price. Journal of Economic Psychology, 18, 487-503.

Kristensen, H., \& Gärling, T. (1997b). The effects of anchor points and reference points on negotiation process and outcome. Organizational Behavior and Human Decision Processes, 71, 85-94.

Kristensen, H., \& Gärling, T. (2000). Anchor points, reference points, and counteroffers in negotiations. Group Decision and Negotiation, 9, $493-505$.

Lacetera, N., Pope, D., \& Sydnor, J. (2012). Heuristic thinking and limited attention in the car market. American Economic Review, 102, $2206-2236$.

Mason, M. F., Lee, A. J., Wiley, E. A., \& Ames, D. R. (2013). Precise offers are potent anchors: Conciliatory counteroffers and attributions of knowledge in negotiations. Journal of Experimental Social Psychology, 49, 759-763.

Medvec, V., \& Galinsky, A. (2005). Increase the final value of the deal: Presenting your counterpart with several offers leads to better outcomes for the dealand the relationship. Harvard Business Review, 8, 4-6.

Miller, N., \& Sklarz, M. (1987). Pricing strategies and residential property selling prices. Journal of Real Estate Research, 2, 31-40.

Monroe, K. (1979). Pricing: Making profitable decisions. New York: McGraw-Hill.

Neale, M., \& Bazerman, M. (1991). Cognition and rationality in negotiation. New York: Free Press.

Niederle, M., \& Vesterlund, L. (2011). Gender and competition. Annual Review of Economics, 3, 601-630.

Northcraft, G. B., \& Neale, M. A. (1987). Experts, amateurs, and real estate: An anchoring-and-adjustment perspective on property pricing decisions. Organizational Behavior and Human Decision Processes, 39, 84-97.

Palmon, O., Smith, B., \& Sopranzetti, B. (2004). Clustering in real estate prices: Determinants and consequences. Journal of Real Estate Research, 26, 115-136.

Poltrock, S., \& Schwartz, D. (1984). Comparative judgments of multidigit numbers. Journal of Experimental Psychology: Learning, Memory, and Cognition, 10, $32-45$.

Pope, D., Pope, J., \& Sydnor, J. (2014). Focal points and bargaining in housing markets. Mimeo.

Raskovich, A. (2007). Competition or collusion? Negotiating discounts off posted prices. International Journal of Industrial Organization, 25, $341-354$.

Schindler, R., \& Kibarian, T. (1996). Increased consumer sales response through use of 99-ending prices. Journal of Retailing, 72, 187-199.

Schindler, R., \& Kirby, P. (1997). Patterns of rightmost digits used in advertised prices: Implications for nine-ending effects. Journal of Consumer Research, 24, $192-201$.

Schindler, R., \& Wiman, A. (1989). Effects of odd pricing on price recall. Journal of Business Research, 19, 165-177.

Seagraves, P., \& Gallimore, P. (2013). The gender gap in real estate sales: Negotiation skill of agent selection? Real Estate Economics, 41, 600-631.

Seiler, M., Madhavan, P., \& Liechty, M. (2012). Toward an understanding of real estate homebuyer internet search behavior: An application of ocular tracking technology. Journal of Real Estate Research, 34, 211-241.

Seiler, M. J., Seiler, V. L., Harrison, D. M., \& Lane, M. A. (2013). Familiarity bias and perceived future home price movements. Journal of Behavioral Finance, 14, $9-24$.

Stiving, M., \& Winer, R. (1997). An empirical analysis of price endings using scanner data. Journal of Consumer Research, 24, 57-67.

Stroeker, N., \& Antonides, G. (1997). The process of reaching an agreement in second-hand markets for consumer durables. Journal of Economic Psychology, $18,341-367$.

Thomas, M., \& Morwitz, V. (2005). Penny wise and pound foolish: The left-digit effect in price cognition. Journal of Consumer Research, 32, 54-64.

Thomas, M., \& Park, J. (2014). The precision effect: How numerical precision influences everyday judgments. In E. Wilhelms \& V. Reyna (Eds.), Neuroeconomics, judgment, and decision making. Psychology Press.

Thomas, M., Simon, D. H., \& Kadiyali, V. (2010). The price precision effect: Evidence from laboratory and market data. Marketing Science, 29, 175-190.

Twedt, D. (1965). Does the '9 fixation' in retail pricing really promote sales? Journal of Marketing, 29, 54-55.

Walters, A., Stuhlmacher, A., \& Meyer, L. (1998). Gender and negotiator competitiveness: A meta-analysis. Organizational Behavior and Human Decision Processes, 76, 1-29.

Wang, R. (1995). Bargaining versus posted-price selling. European Economic Review, 39, 1747-1764.

White, S. B., Valley, K. L., Bazerman, M. H., Neale, M. A., \& Peck, S. R. (1994). Alternative models of price behavior in dyadic negotiations: Market prices, reservation prices, and negotiator aspirations. Organizational Behavior and Human Decision Processes, 57, 430-447. 